Universidad de Lima

Facultad de Psicología

Carrera de Psicología

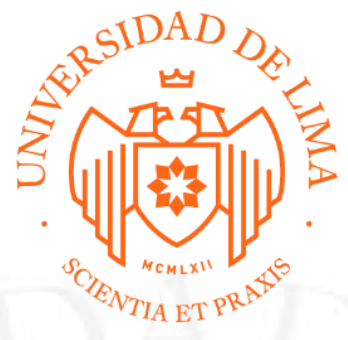

\title{
CREACIÓN DE DISEÑO INSTRUCCIONAL PARA EL DESARROLLO DE COMPETEN- CIAS QUE ESTIMULEN LA CAPACIDAD DE INNOVAR EN LÍDERES EN UNA EMPRESA PRIVADA DE LIMA METROPOLITANA
}

Trabajo de suficiencia profesional para optar el título profesional de licenciado en Psicología

Irene Pastor Mas

Código 20090843

Asesor

Mónica Fernandez Otoya

Lima - Perú

Marzo del 2020 


\section{CREACIÓN DE DISEÑO INSTRUCCIONAL PARA EL DESARROLLO DE COMPETEN- CIAS QUE ESTIMULEN LA CAPACIDAD DE INNOVAR EN LÍDERES EN UNA EMPRESA PRIVADA DE LIMA METROPOLITANA}




\section{RESUMEN}

En la carrera de transformación digital que se viene dando en el sector de cosméticos encontramos en esta empresa una oportunidad de mejora en la implementación de soluciones digitales para la atención de su mercado, para lo cual se identificó que un atributo importante para la innovación es el liderazgo servidor. En este sentido el presente trabajo tuvo como objetivo desarrollar las competencias de escucha activa y trabajo colaborativo propias del líder servidor como parte de la generación de una cultura de innovación. Para ello se capacitaron a 36 líderes de las áreas comerciales de quienes se tenía un resultado general sobre el estilo de liderazgo derivado de la prueba psicométrica de Diagnóstico de Innovación C3. Se realizó un diseño instruccional con base en el constructivismo y los métodos de evaluación del proceso fueron diversos. Se logró incorporar en los líderes prácticas asociadas al trabajo colaborativo y a la escucha activa para que sean utilizadas en el desarrollo de sus futuros proyectos, así como en el direccionamiento de equipos. Consecuentemente, los líderes de las áreas comerciales lograron adoptar las competencias de escucha activa y trabajo colaborativo referidas al líder servidor como parte inicial de la generación de una cultura de innovación.

Palabras clave: Escucha activa, Trabajo colaborativo, Liderazgo; Innovación 


\begin{abstract}
In the digital transformation career that has been taking place in the cosmetics sector we find in this company an opportunity for improvement in the implementation of digital solutions for the attention of its market, for which it was identified that an important attribute for the Innovation is server leadership. In this sense, this work aimed to develop the skills of active listening and collaborative work of the server leader as part of the generation of an innovation culture. For this, 36 leaders from the commercial areas of those who had a general result were trained on the leadership style derived from the $\mathrm{C} 3$ Innovation Diagnostic Psychometric Test. An instructional design was made based on constructivism and the methods of process evaluation were diverse. It was incorporated into the practical leaders associated with collaborative work and active listening during the development of their projects, as well as in team management. Consequently, the leaders of the commercial areas managed to adopt the competences of active listening and collaborative work referred to the server leader as an initial part of the generation of a culture of innovation.
\end{abstract}

Keywords; Active listening, Collaborative work, Leadership; Innovation 


\section{TABLA DE CONTENIDO}

CAPÍTULO I: CONTEXTUALIZACIÓN DE LA PROBLEMÁTICA . 1

1.1 Descripción del Problema ........................................................................

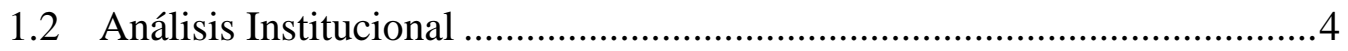

CAPÍTULO II: MARCO TEÓRICO Y ANTECEDENTES .........................................

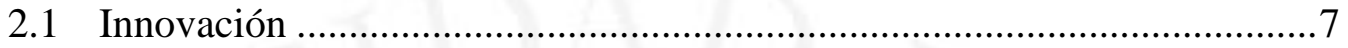

2.1.1 Conceptualización de la Innovación .....................................................

2.1.2 Teoría de la creatividad de Teresa Amabile .............................................8

2.1.3 La importancia de la Innovación en las empresas .................................... 9

2.1.4 Competencias asociadas a la innovación .............................................. 10

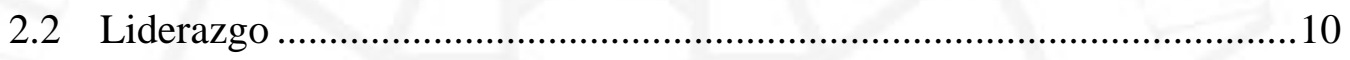

2.2.1 Conceptualización del Liderazgo......................................................... 10

2.2.2 Los tipos de liderazgo ....................................................................... 11

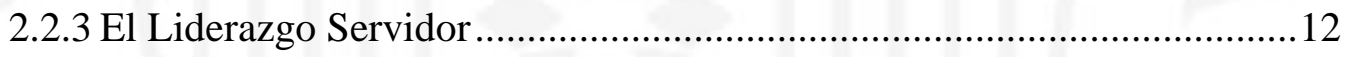

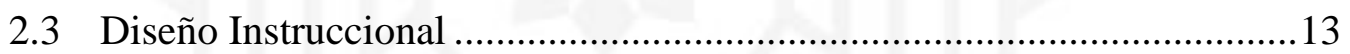

2.3.1 Teoría de Diseño Instruccional desde el enfoque constructivista.............13

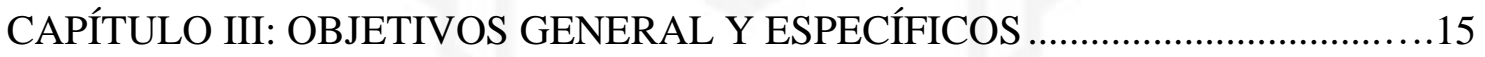

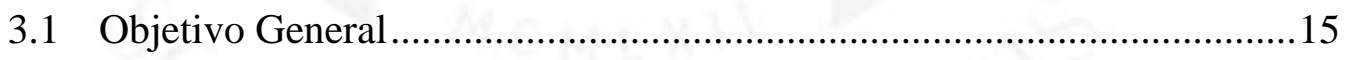

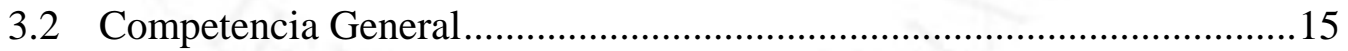

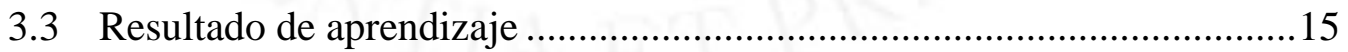

CAPÍtUlo IV: METODOLOGÍA DE LA EVALUACIÓN Y DE LA

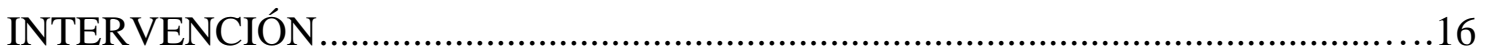

4.1 Evaluación de la línea base ......................................................................16

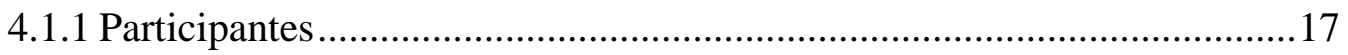

4.1.2 Técnicas y/o instrumentos de evaluación/diagnóstico ...............................17

4.1.3 Procedimientos de evaluación de línea base ............................................18 
4.2 Implementación

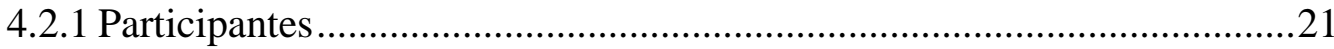

4.2.2 Instrumentos o herramientas de implementación/intervención .................21

4.2.3 Procedimiento de implementación......................................................23

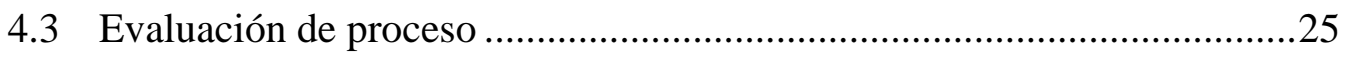

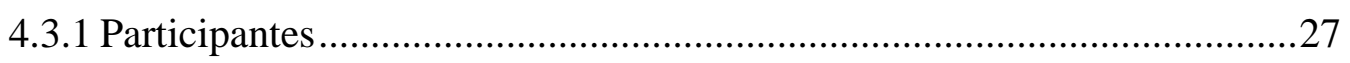

4.3.2 Técnicas y/o instrumentos de evaluación/diagnóstico .............................27

4.3.3 Procedimiento de evaluación de proceso ..............................................27

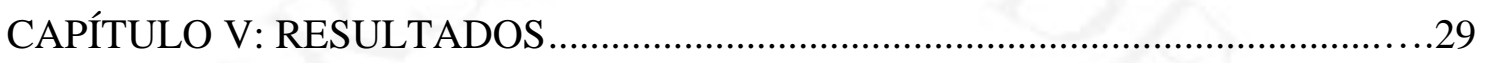

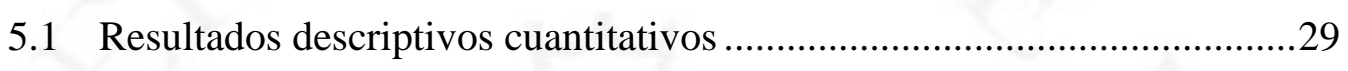

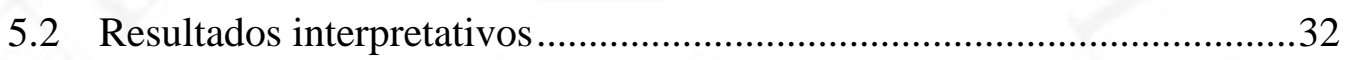

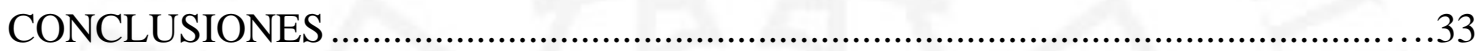

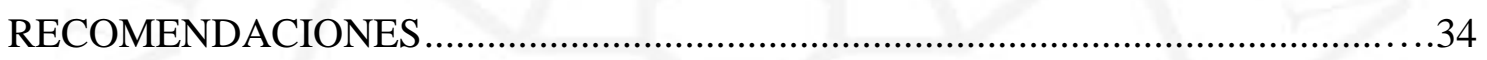

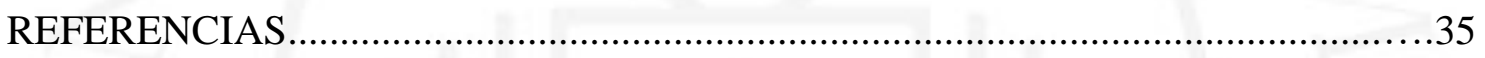

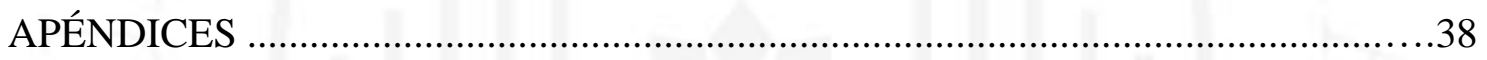




\section{ÍNDICE DE TABLAS}

Tabla 4.1 Matriz organizativa de la implementación de los talleres .............................20

Tabla 4.2 Matriz de Diseño Instruccional Taller 1 .....................................................22

Tabla 4.3 Matriz de Diseño Instruccional Taller 2 .......................................................23

Tabla 5.1 Recopilación de resultados del taller 1 de Cambio de Mindset e Introducción

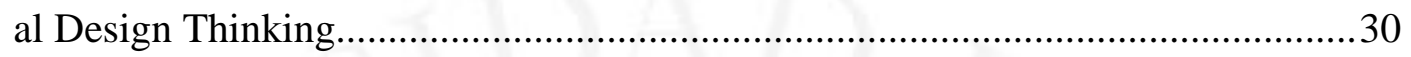




\section{ÍNDICE DE APÉNDICES}

APÉNDICE 1 FICHA TÉCNICA DE INSTRUMENTO DE EVALUACIÓN. .39 APÉNDICE 2 DISEÑO INSTRUCCIONAL TALLER 1 - CAMBIO DE MINDSET E INTRODUCCIÓN AL DESIGN THINKING ...............................................4 40

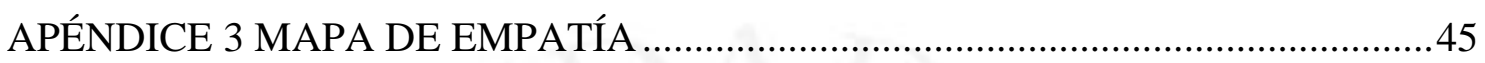

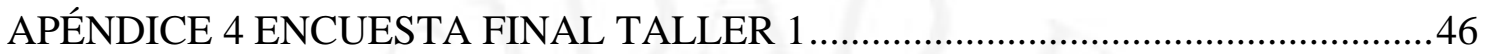

APÉNDICE 5 DISEÑO INSTRUCCIONAL TALLER 2 - METODOLOGÍAS

ÁGILES E INTRODUCCIÓN A SCRUM . .47

APÉNDICE 6 MATRIZ DE IDENTIFICACIÓN DE CARACTERÍSTICAS DE

ESTILO DE TRABAJO .51

APÉNDICE 7 ENCUESTA FINAL TALLER 2 …...................................................52

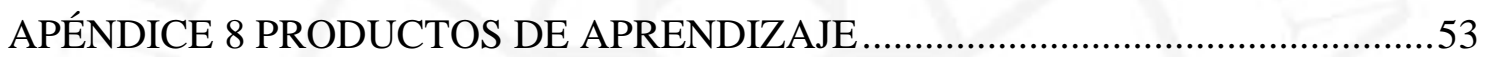

APÉNDICE 9 MATRIZ ORGANIZATIVA DEL PROYECTO ....................................54 


\section{CAPÍTULO I: CONTEXTUALIZACIÓN DE LA PRO- BLEMÁTICA}

\subsection{Descripción del Problema}

En la actualidad, estamos inmersos en un mundo en donde la innovación ocupa un lugar muy importante en los nuevos modelos de negocio. Según Kelley y Littman (2016) la necesidad de fomentar una cultura de innovación es cada vez más inminente en las compañías, ya que aseguran que es uno de los indicadores de éxito más importantes. Asimismo, los autores advierten que la innovación no ocurre de forma automática, sino que requiere de personajes específicos que accionen sobre la cadena de procesos para llevar a cabo y concretar un proyecto; y tales personajes deben tener o desarrollar capacidades y habilidades que favorezcan los entornos para la innovación; por ello, es necesario preparar a los líderes de las organizaciones para que puedan hacer frente a la gestión de la innovación en las compañías que encabezan, con lo cual, el identificar tales capacidades y habilidades, resulta ser el primer eslabón en la ruta hacia la innovación.

Desarrollar las capacidades para la innovación no resulta ser una tarea fácil ya que requiere un cambio de paradigma y en la forma de gestionar de los altos ejecutivos. Estos cambios radican en la manera de dirigir y entender a un equipo de trabajo, así como en la adquisición de nuevas habilidades y prácticas de dirección de los altos ejecutivos (Vilá, 2011).

En la actualidad, según la Organización Mundial de la Propiedad Intelectual, tanto las economías desarrolladas como las que están en desarrollo promueven la innovación con el objetivo de lograr el desarrollo social y económico, lo cual evidencia la importancia que ésta tiene dentro de la sociedad, pues aseguran que el impacto de la innovación no sólo está en empresas de alta tecnología, sino en todos los ámbitos (Cornell University, INSEAD, WIPO, 2019).

Según el Foro Económico Mundial, fundación sin fines de lucro que reúne anualmente a los principales líderes empresariales, políticos e intelectuales para analizar las dificultades más relevantes que afronta el mundo, un reto crítico para América Latina es 
posicionarse en su capacidad de innovación, esto se debe a la manera convencional de pensar de los líderes, la carencia de apertura y confianza, y a la falta de colaboración existente en las empresas (Framil y Ovanessoff, 2016).

Además, en un estudio realizado por López (2014) donde analiza los factores psicosociales que caracterizan a los equipos innovadores, encuentra diferencias significativas en la dimensión de equipos de trabajo entre el grupo que realizaba alguna actividad innovadora que reveló contar con una mayor cohesión debido al respeto y cooperación entre los miembros del grupo, versus el grupo de contraste, en done la cohesión fue significativamente menor.

En lo que respecta a nuestra realidad nacional, un estudio llevado a cabo por Korn Ferry y la Universidad Peruana de Ciencias aplicadas tuvo como objetivo analizar el estilo de liderazgo de altos ejecutivos. Para ello, se evaluó a 355 líderes en Perú utilizando la herramienta Decision Styles de Korn/Ferry International, la cual en base a los resultados, ha definido a un gerente de mando medio como "Un ejecutivo convencional respecto a las estrategias que planifica, propone y desarrolla y que, posiblemente, prefiere adoptar lineamientos que le son entregados desde arriba en lugar de innovar o generar cambios que rompa parámetros del statu quo" (Gaviria, Ratti, Quiroga, Ontaneda y Galdós, 2014, p. 53). Asimismo, asocian al líder peruano como "Un ejecutivo que tiende a dirigir según su parecer. Se orienta a la calidad y lógica, pudiendo dejar de lado la oportunidad de explorar nuevas ideas y enfoques a través del trabajo en equipo" (Gaviria et al., 2014, p. $54)$.

Por consiguiente, dos estudios que evalúan el desarrollo de la Innovación elaborados por la Organización Mundial de la Propiedad Intelectual (OMPI), organismo que fomenta el uso y protección de obras del intelecto humano, y el Foro Económico Mundial, sitúan al Perú en el puesto 70 de 127 y 113 de 137 países respectivamente. Ambos estudios ponen en manifiesto la importancia de desarrollar la innovación en el país revelando que la obtención de resultados favorables depende de ciertas características tales como un capital humano apto, acceso al financiamiento, entre otros. En este sentido, se encontró que el gasto en innovación en las empresas privadas estuvo orientado principalmente a la adquisición y adopción de tecnología que a la generación de la misma, con lo cual se evidencia que la capacidad de innovación del Perú es aún bastante limitada en su capital humano (Velapatiño y Perea, 2018). 
Asimismo, un estudio desarrollado en 3535 empresas que operan en Lima en los sectores de comercio, manufactura y transporte elaborado por los autores Novella, Alvarado, Rosas y González-Velosa (2019) revela que las habilidades más difíciles de encontrar son el trabajo en equipo, la responsabilidad, la comunicación asertiva, resolución de problemas, entre otras. Además, los autores Alvarado, Rosas y González-Velosa (2019) afirman que:

"la deficiencia de habilidades entre los trabajadores limita la capacidad de las firmas de desarrollar nuevos productos o servicios, provocando pérdidas en los negocios" (p. 9).

Es entonces a partir de estas conclusiones que se evidencia la necesidad de desarrollar capacidades y habilidades tales como el trabajo en equipo o colaborativo, la capacidad de escucha activa y la empatía en los líderes para que puedan enfrentarse a los desafíos que trae el futuro.

Además, tal como lo menciona Giuliana Pacheco, líder profesional de Gestión Humana de una importante empresa en Perú, es sustancial favorecer una cultura colaborativa en donde se desarrolle la habilidad de trabajar en equipo con el fin de buscar objetivos colectivos para brindar las mejores soluciones a los clientes y/o mejorar los servicios (“¿Como influye la transformación cultural en una empresa?”, 2019, párr. 3).

Tal es el caso que en el sector de venta directa y cosméticos se vienen desarrollando canales alternativos como el e-commerce para cubrir las necesidades de los nuevos clientes, quienes buscan inmediatez, además de otras exigencias. Es aquí donde la empresa "UQ" busca una oportunidad de mejora, puesto que los proyectos enfocados en desarrollar nuevas propuestas de valor en torno a esta era digital, aún requieren de mayor agilidad para enfrentarse a las demandas del mercado y por lo tanto de líderes que gestionen equipos, procesos y proyectos con habilidades y capacidades adecuadas para lograr la innovación y agilidad que se requiere. Sin embargo, cabe resaltar que el reto para "UQ" no recae en la implementación del canal e-commerce, sino en cuestionar el modelo de negocio que hoy se viene desarrollando y encontrar soluciones que aseguren la continuidad de la gestión comercial existente por medio de una fuerza de ventas independiente e incluir un nuevo canal de venta que posicione a la compañía en un nuevo mercado. 
Es así que en "UQ", se establecieron diversos procesos para implementar una Cultura enfocada en la Innovación, siendo uno de los primeros hitos, la ejecución de una medición de la Cultura de Innovación.

Luego de la medición, se presentaron los resultados a Gerencia General y a partir del análisis de los mismos, surgió la necesidad de tomar acciones relacionadas a la movilización de los líderes, ya que de acuerdo a Rivera (2016), para generar cambios inminentes en la cultura y por ende en la organización, se requieren de líderes con formas diferentes de trabajar y movilizar a su equipo para lograr transformar los procesos y conseguir los resultados que hoy en día busca la organización. Si bien los resultados de la dimensión de liderazgo obtenidos a nivel compañía fue de 54 puntos, lo cual revelaba un desarrollo promedio de comportamientos de liderazgo que promueven la innovación, aquellas áreas comerciales del negocio de las cuales se espera surjan procesos y proyectos innovadores, revelaron contar con puntajes entre 4 y 34 puntos, lo cual evidenciaba la falta de desarrollo de competencias en los líderes para promover la innovación. Esto se vio además reflejado en los resultados desfavorables de los siguientes ítems asociados a la dimensión de liderazgo: "mi jefe directo está abierto a nuevas ideas", "mi jefe directo brinda comentarios o sugerencias constructivas sobre mi trabajo", "mi jefe directo valora los aportes individuales a los proyectos", "en mi área hay personas o líderes que nos estimulan y motivan para innovar en nuestro trabajo".

Entonces, debido a los resultados mencionados anteriormente obtenidos de esta empresa del rubro de venta directa y cosmético, es que se genera la necesidad de plantear un cronograma de actividades y acciones en busca del desarrollo de nuevas competencias en los líderes y en las formas de abordar los distintos proyectos de la compañía.

\subsection{Análisis Institucional}

El presente trabajo se realiza en una empresa del rubro de venta directa de productos de belleza y cosméticos a la cual llamamos "UQ". Es una empresa de capital peruano fundada en los años 60 que por su crecimiento fue expandiéndose en 10 países de América y Europa. Sus principales pilares estratégicos son sus productos y su esquema comercial el cual radica en la venta directa por catálogo por medio de una fuerza de ventas independiente. 
Dentro de sus principales competidores de venta directa en el mercado se encuentran 3 empresas que también ofrecen productos de belleza y cosméticos, sin embargo, el rubro de venta directa está compuesto por compañías que ofrecen diversos productos como lencería, de salud y bienestar, de hogar, entre otros. Las principales amenazas de esta empresa la constituyen los canales de venta alternativos que están desarrollando sus competidores lo cual es importante dar a conocer para reiterar la necesidad de innovación en la compañía.

Esta empresa está conformada por aproximadamente 1800 colaboradores distribuidos en 3 estructuras de empresas diferenciadas en unidades de Negocio, estas son: la unidad Corporativa, la de Operaciones y la unidad Comercial. Este estudio estuvo basado en la unidad Comercial, la cual consta de aproximadamente 450 colaboradores que integran 10 áreas de la compañía. La misión de "UQ" radica en transformar la vida de las personas llevando belleza con productos innovadores y con altos estándares de calidad, y brindar oportunidad de crecimiento en las familias gracias al objetivo de crecimiento de sus ventas. Es así que "UQ" tiene como visión estar dentro de las 20 mejores empresas de cosméticos del rubro de venta directa del mundo, con lo cual para mantenerse a la vanguardia y seguir impulsando el crecimiento de la compañía, es importante que cuente con líderes que fomenten la generación de una cultura de innovación.

“UQ", al ser una empresa del rubro de venta directa está regulada por la Cámara Peruana de Venta Directa (Capevedi) la cual tiene como objetivo representar los intereses del sector y el de sus asociados ante los organismos públicos, las asociaciones de consumidores y la opinión pública (CAPEVEDI, s.f.), por el Gremio Peruano de Cosmética e Higiene (Copecoh) que busca fortalecer el marco económico, comercial y regulatorio para el desarrollo del sector (COPECOH, s.f.), y por la Dirección General de Medicamentos, Insumos y Drogas (Digemid) quien se encarga de la regulación por productos sanitarios (Ministerio de Salud, s.f.).

Considerando algunos datos del sector, se sabe que la venta directa creció durante el primer trimestre del año 2019 por encima de la economía peruana, obteniendo un aumento de 4,9 \% en relación al mismo periodo del año 2018. Acorde a ello, la estimación que se hacía para el cierre del año 2019 fue de un crecimiento de 4,3\% de expansión total del rubro, no obstante este sólo llegó a crecer un 3,3\% en el 2019, cifra que tuvo un impacto no muy positivo en "UQ", puesto que además disminuyó su participación en el mercado. Asimismo, Ángel Acevedo, presidente de Copecoh, señaló que la inestabilidad 
política es un factor que impacta en el sector, por lo cual existe una incertidumbre grande respecto al crecimiento de este para los años 2020 y 2021, teniendo entonces un reto mayor ante las exigencias del mercado (Inga, 2019, párr. 3).

Por otro lado, de acuerdo a un estudio realizado por Molina (2019), se sabe que la venta directa concentra hoy en día el $48 \%$ de las ventas, mientras que el canal retail ha logrado un avance importante, teniendo una concentración del 50\%, por su lado, el canal online empieza a tomar importancia, aunque hoy genera tan solo el 1\% de las ventas. Sin embargo, el autor estimó en su estudio que las ventas en línea aumentarán alrededor del $55 \%$ a través de dispositivos móviles y de $30 \%$ a través de computadoras.

Por lo tanto, se identifica como un reto importante para las compañías de este sector, la transformación de su esquema comercial y por ende de sus procesos. Cabe resaltar que varias empresas del rubro han empezado a explorar muy de cerca el mundo del e-commerce, sin embargo, "UQ" aún tiene que realizar diversos cambios dentro de su gestión organizacional para lograr hacer frente a los retos que trae la transformación digital, producto de la cultura de innovación que se viene implementando en las empresas del sector, y poder así alcanzar los avaneces ya realizados por sus competidores.

Es así que luego del análisis realizado del Diagnóstico de Innovación llevado a cabo en "UQ" y de los retos expuestos líneas arriba, se desprende la urgencia de intervenir en el punto expuesto anteriormente sobre liderazgo en donde se identifica la necesidad imperativa de desarrollar en los líderes capacidades y habilidades que promuevan los entornos para la innovación. 


\section{CAPÍTULO II: MARCO TEÓRICO Y ANTECEDEN- TES}

\subsection{Innovación}

\subsubsection{Conceptualización de la Innovación}

Una de las definiciones más conocidas y promulgadas acerca del concepto de innovación es aquella elaborada por La Organización de Cooperación y Desarrollo Económico (OCDE), quien en el Manual de Oslo, manual desarrollado conjuntamente con Eurostat recaban una serie de datos relativos a la ciencia, la tecnología y la innovación. En este documento, los autores señalan que la innovación es "la introducción de un nuevo, o significativamente mejorado, producto (bien o servicio), de un proceso, de un nuevo método de comercialización, o de un nuevo método organizativo, en las prácticas internas de la empresa, la organización del lugar de trabajo o las relaciones exteriores" (OCDE y Eurostat, 2006, p. 56). De igual manera, afirman que la naturaleza de la innovación depende del interés de las empresas en cómo quieran enfocar la innovación (OCDE y Eurostat, 2006).

En este contexto, los autores Bellomusto \& Esquembre (2014) también definen en su libro de la Innovación y gestión estratégica de proyectos el concepto de Innovación como la implementación de una novedad en la operación de una compañía motivada por la necesidad de mejora de la valoración de los clientes y el incremento de rentabilidad de la empresa. Ellos clasifican la innovación en 3 tipos: i) de producto, ii) de proceso y iii) del modelo de negocio u organizacional.

Por otro lado, las psicólogas Cifuentes y Londoño (2017) el concepto de innovación en su investigación de "Los Rasgos Identificativos que promueven la Cultura de la Innovación en las organizaciones", como un término amplio que no solo involucra la creación de cosas nuevas, sino que considera problemáticas organizacionales como las formas de trabajo, la aplicación de nuevas metodologías, la disminución de tiempo y actividades que no generan valor, y la inclusión de tecnología a favor de la organización. 
Del mismo modo, es entonces necesario destacar que la innovación empresarial tiene una estrecha relación con la cultura de la compañía, ya que de acuerdo a lo señalado en el Manual de Oslo, las empresas que buscan el tipo de innovación organizacional, deben introducir nuevas estructuras organizativas y generar nuevas prácticas, normas y valores orientadas a una cultura que impulse la innovación (OCDE y Eurostat, 2006).

En este sentido, Souto (2015) menciona que existen dos aspectos básicos en la gestión de una cultura de innovación: la dirección de personas y el trabajo en equipo. Ellos mencionan que el primero está referido al tipo de liderazgo que se ejerce para conducir a las personas a un objetivo y que el segundo no consiste únicamente en hacer trabajar juntas a un grupo de personas, sino que es necesario guiar la cooperación e interacción entre ellos creando un ambiente abierto y participativo. Con esto, los autores recalcan que la cultura de innovación consiste en incentivar también una cultura de aprendizaje de nuevas habilidades y competencias que orienten a las personas a reorganizar su gestión individual hacia una gestión colaborativa para la consecución de objetivos comunes.

Por lo tanto, se puede ver que existen diferentes perspectivas sobre la innovación y a continuación se explicará brevemente la teoría de la creatividad de Teresa Amabile sobre la cual se basa el instrumento utilizado en el presente trabajo para el Diagnóstico inicial que se llevó a cabo.

\subsubsection{Teoría de la creatividad de Teresa Amabile}

La teoría de la creatividad de Amabile (1996) presenta el concepto de innovación teniendo como base la definición de creatividad la cual es referida a la creación de nuevas ideas en cualquier campo. En línea con ello, define a la innovación como "aplicar con éxito ideas creativas en una organización" (p.1).

Según Amabile (1996), la creatividad en una organización es integrada tanto por factores humanos, así como por variables del contexto laboral. Por lo tanto, para ella, la innovación dentro de una compañía es impulsada por 3 componentes dentro de su modelo: el dominio de conocimientos, el pensamiento creativo y la motivación frente a la tarea. 


\subsubsection{La importancia de la Innovación en las empresas}

Como se ha mencionado a inicios de este estudio, la innovación es una necesidad inminente en el mundo en el cual vivimos hoy en día, esto debido a las exigencias de los clientes anteriormente expuestas, así como al incremento de la competitividad. De acuerdo a ello, se sabe que, hace algunos años, los modelos de gestión de las empresas solían ser más estáticos, sin embargo, según lo señalado por el autor Abraham Muinelo en su artículo sobre la Cultura de Innovación, actualmente existe un radical cambio en la gestión ya que el análisis constante, el conocimiento y la visión estratégica son fundamentales para la sobrevivencia de una compañía innovadora (Muinelo, 2018, párr. 2).

Del mismo modo, Haro, Córdova, y Alvarado (2017), señalan que para que las compañías puedan ser consideradas competitivas y sobrevivir en el mercado, deben tener la capacidad de innovar y retar constantemente al mercado con sus ofertas de productos/servicios. Ellos consideran que hay 4 aspectos esenciales que revelan la necesidad de innovación, estos son: i) la globalización progresiva de mercados, ii) el ciclo de vida reducido de productos, iii) los rápidos cambios tecnológicos y iv) los cambios continuos en patrones de compras de los clientes. Finalmente, los autores aseguran que la innovación se encuentra estrechamente ligada con la estrategia empresarial y para que ambas sean desarrolladas es necesario el análisis de otros 4 aspectos fundamentales: i) la misión, ii) la cultura, iii) el diagnóstico inicial y iv) el análisis del entorno.

Por otro lado, en un artículo realizado por Jean Pierre Seclén, en donde tiene como objetivo analizar la importancia de la gestión de innovación de las empresas, el autor advierte acerca de la necesidad de que en el Perú se potencien las competencias que mejoren la capacidad de absorción de nuevos conocimientos e impulsen el desarrollo de la innovación (Seclén, 2016).

Finalmente, en un estudio elaborado por Jhon Tapia en una entidad pública del país, se exponen los factores principales que determinan el éxito de cualquier tipo de innovación. Estos son los siguientes: i) asignación clara de recursos y presupuestos, ii) rediseño organizacional con estructuras de trabajo y espacios de innovación, iii) desarrollo de capacidades, motivaciones y oportunidades de innovación en los empleados, iv) adecuada gestión de riesgos e incertidumbres y v) adecuada gestión del conocimiento (Tapia, 2018). 


\subsubsection{Competencias asociadas a la innovación}

De acuerdo a lo revisado en párrafos anteriores, se sabe que la innovación es favorecida tanto por el entorno como por el comportamiento de quienes conforman la organización. Respecto a ello, Ferrer (2018) menciona que la gestión del conocimiento favorece a que los líderes puedan impulsar la innovación en sus compañías, con lo cual para el logro efectivo de esta gestión del conocimiento se torna necesario incentivar ambientes de trabajo colaborativo en donde las personas puedan estar dispuestas a compartir y escuchar las opiniones del grupo.

En consecuencia con lo mencionado anteriormente, es que se definen dos competencias fundamentales para que los líderes promuevan los espacios de innovación en la compañía: la escucha activa y el trabajo colaborativo. La escucha activa (EA), de acuerdo a lo mencionado por Rogers está estrechamente ligada a su concepto de comprensión empática que trata de estimular la libre expresión y reconocer el significado real de lo mencionado por el otro (como se citó en Subiela, Abellón, Celdrán, Manzanares, y Satorres, 2014). Además, los autores afirman que para lograr una escucha activa efectiva es necesario: dejar de hablar, que el interlocutor se sienta en confianza, demostrar disposición de escucha, eliminar distracciones, no interrumpir, evitar criticar y preguntar en caso sea necesario (Subiela et al., 2014). En cuanto a trabajo colaborativo (TC), el concepto es definido por López (2017) como "un conjunto de personas que se organizan en un ambiente de cooperación para alcanzar objetivos comunes repartiendo responsabilidades y definiendo un proceso, buscando obtener resultados positivos" (p.22).

Por lo tanto, según Ferrer (2018), los líderes que entienden primero las necesidades de sus seguidores logran alinearse con ellos y guiarlos de la mejor manera para favorecer a la creación de nuevos conocimientos y lograr así la innovación en la compañía.

\subsection{Liderazgo}

\subsubsection{Conceptualización del Liderazgo}

Existen diversas conceptualizaciones de liderazgo en la literatura, sin embargo, en el presente trabajo presentaremos sólo algunas de ellas para enmarcar el estilo de liderazgo que nos interesa, así como los comportamientos asociados a este que buscamos desarrollar en la presente investigación. 
Para comenzar, queremos exponer la definición propuesta por John Maxwell, quien se refiere al líder como un sinónimo de influencia. Él considera que el liderazgo se inicia con la capacidad de conseguir seguidores y no como la capacidad de alcanzar una posición (Maxwell, 1993).

Por su lado, Contreras (2016) hace referencia al liderazgo teniendo como base la teoría de los rasgos, la cual comprende al liderazgo de acuerdo a características específicas que lo diferenciaban del resto de personas comunes. No obstante, también afirma que luego de revisar diversas investigaciones de liderazgo, se sabe que es también necesario considerar el rol que tienen las situaciones en el ejercicio de liderazgo, ya que existen ámbitos donde funcionan ciertos estilos de liderazgo y otros en los que no.

Por último, Robbins (2018) hace también referencia al líder como a alguien que tiene la capacidad de influir en otros y que crea autoridad frente al resto. Para este autor, el liderazgo es un proceso de dirigir a un grupo e influir en el mismo para lograr objetivos comunes.

\subsubsection{Los tipos de liderazgo}

A lo largo del estudio del concepto de liderazgo se han realizado, no solo diversas definiciones, sino que también se ha indagado en la distinción de tipos de liderazgo que hacen referencia a comportamientos específicos, por lo cual revisaremos algunos de ellos para finalmente mencionar aquel que se ha tomado como base en el desarrollo del presente trabajo para el direccionamiento de los líderes de la organización, hacia la innovación.

En primer lugar, mencionaremos el Liderazgo Transaccional que surge en la Etapa de las Teorías del Nuevo Liderazgo, a principios de los años 80. Su base radica en la fórmula de estímulo recompensa. Sin embargo, la restricción de este modelo es que no existe una relación de consenso entre el líder y los subordinados para conseguir un fin superior (Pantoja y Suárez, 2017).

Por otro lado, es importante mencionar el Liderazgo Transformacional introducido por Burns y desarrollado posteriormente por Bass en su Teoría de Liderazgo Transformacional, la cual identifica cuatro componentes básicos en el líder referido al carisma e influencia, inspiración motivacional, atención a las diferencias individuales y la estimulación intelectual mediante el cuestionamiento (Hermosilla, Amutio, Da Costa y Páez, 2016). 
Para terminar, se ha identificado un tipo de liderazgo que involucra diversos comportamientos que guían a los líderes hacia un comportamiento de favorecedor de entornos. Nos referimos al Liderazgo Servidor. Este concepto fue introducido por Robert Greenlaf quien afirma que el Líder Servidor es aquel que inicia, proporciona ideas, las estructura y corre riesgos de fracaso sin temer al camino incierto (Greenleaf, 1977).

\subsubsection{El Liderazgo Servidor}

Tal como se mencionó en el párrafo anterior, el Liderazgo Servidor fue un concepto introducido por Robert Greenleaf, para el autor, la teoría del líder servidor comienza con el sentimiento natural de querer servir primero a su equipo y es mediante esa elección consciente de servicio que lleva a las personas a aspirar a liderar. (Greenleaf, 1977).

Por otro lado, Brugioni describe, por medio de un artículo, aquellas características asociadas al líder servidor. Ella menciona que este tipo de liderazgo se basa en la escucha, en el asesoramiento y en el apoyo de los colaboradores, resaltando además la oposición completa frente a un liderazgo autoritario y jerárquico. Respecto a los comportamientos asociados, se detallan los siguientes: el respeto, el intercambio de opiniones, la ayuda, la empatía, el aliento, la ayuda con el aprendizaje nuevo, la convivencia y el espíritu de colaboración (Brugioni, 2018).

Por último, un estudio realizado por Williams y Atinc (2017) que tuvo como base la teoría de la creatividad de Amabile buscó examinar la relación entre el líder servidor y la habilidad política, resaltó que debido a que este tipo de líderes buscan atender a las necesidades de sus seguidores de manera auténtica y empoderarlos, es que se reconoce como un liderazgo adecuado para aquellas organizaciones que buscan la innovación, puesto que el rol del líder radica en ayudar a sus equipos a maximizar su potencial creativo. Esta investigación revela que además de las características individuales de colaboradores creativos, los líderes y las relaciones que ellos fomenten con sus equipos de trabajo afectan significativamente en el nivel de creatividad en la organización.

Tal como se ha expuesto líneas arriba, a lo largo de los años se han estudiado diversos tipos de liderazgo, sin embargo para considerar al Liderazgo Servidor como uno de los tipos de liderazgo más influyentes en la cultura de Innovación a continuación se expondrán algunos puntos relevantes. 
Según Naranjo-Valencia y Calderón-Hernández (2015), el líder es reconocido como uno de los constructores principales en la cultura de una organización, ya que ellos afirman que el líder suele ser visto como un referente en su comportamiento pudiendo así desarrollar la autonomía, la diversidad, el autocontrol, el reconocimiento y entre otros rasgos de comportamiento que impulsan un ambiente de innovación.

En un estudio realizado por Ying (2016) que tuvo por objetivo introducir niveles de control de rendimiento en la relación entre liderazgo servidor y desempeño de innovación del personal revelaron que existe una correlación positiva de 0.38 entre el liderazgo servidor y el desempeño de innovación del personal sin importar cuál sea el nivel de control de rendimiento. Con este hallazgo, los autores perfeccionaron el campo de estudio del liderazgo servidor y concluyen que las habilidades asociadas al liderazgo servidor tienen un efecto directo con el desempeño de la innovación sin importar cuál sea el control de rendimiento existente en la compañía.

\subsection{Diseño Instruccional}

\subsubsection{Teoría de Diseño Instruccional desde el enfoque constructivista.}

Desde hace varias décadas se han ido desarrollando diversas teorías y modelos de diseño instruccional, pero en esta oportunidad mencionaré específicamente el enfoque constructivista.

No obstante, es igualmente necesario empezar por definir lo que es el diseño instruccional, para lo cual se ha seleccionado la definición de Richey, Fields y Foson, quienes mencionan que "el DI radica en una planificación instruccional sistemática que considera la valoración de necesidades, el desarrollo, la evaluación, la implementación y el mantenimiento de materiales y programas" (como se citó en Belloch, 2012, p. 2).

Asimismo, Rincón (2014) menciona que de acuerdo a la concepción constructivista del aprendizaje, el conocimiento se va desarrollando gracias a las experiencias de los participantes y de su participación activa en la sesión. El autor afirma que la labor del docente radica en la facilitación de situaciones que favorezcan a la construcción de conocimiento por parte de los estudiantes.

Además, Belloch (2012), pone en manifiesto las siguientes premisas que guían el proceso de diseño instruccional constructivista: i) construcción del conocimiento a partir 
de la experiencia, ii) el aprendizaje como interpretación personal del mundo, iii) aprendizaje basado en la realidad con el fin de integrar diversas tareas y iv) aprendizaje gracias a la modificación de representaciones mentales por la llegada de nuevos conocimientos.

Finalmente, en un estudio realizado por Rodríguez, García, Cortes, y Puga (2019) los autores reafirman que los estudiantes en el modelo constructivista son percibidos como personas con conocimientos específicos previos que influenciarán en sus acciones y actitudes. De igual manera, los docentes constructivistas deben adoptar un rol que considere la participación activa de los alumnos con el fin de que aprendan de manera significativa relacionando los nuevos conocimientos con sus propias estructuras y esquemas mentales. 


\section{CAPÍTULO III: OBJETIVOS GENERAL Y ESPECÍFI- $\operatorname{COS}$}

\subsection{Objetivo General}

Desarrollar las competencias de Escucha Activa y Trabajo Colaborativo, propias del liderazgo servidor, a través de un programa formativo desarrollado para los líderes de las áreas comerciales de la compañía.

\subsection{Competencia General}

Escucha Activa (EA): Escuchan y aceptan diferentes opiniones, no se anticipan a brindar una respuesta, no juzgan y no interpretan las propuestas de los colaboradores.

Trabajo Colaborativo (TC): Logran llegar a consensos, intercambian opiniones mediante retroalimentación constante y se apoyan para el logro de los objetivos.

\subsection{Resultado de aprendizaje}

Escucha Activa (EA):

- Consideran la opinión de un compañero del grupo en la discusión haciendo referencia a su idea.

- No emiten juicios sobre las intervenciones de los demás compañeros.

- Esperan que la persona culmine con su idea antes de brindar una respuesta sobre ella.

Trabajo Colaborativo (TC):

- Llegan a un consenso en el grupo

- Brindan retroalimentación sobre las propuestas de sus compañeros

- Participan brindando ideas constructivas para el logro de objetivos del grupo 


\section{CAPÍTULO IV: METODOLOGÍA DE LA EVALUA- CIÓN Y DE LA INTERVENCIÓN}

\subsection{Evaluación de la línea base}

Para tomar la decisión de realizar una intervención a nivel del liderazgo en busca de un cambio que fomente la cultura de innovación en la compañía, se llevó a cabo un proceso de diagnóstico de cultura de innovación en el cual se analizaron los resultados obtenidos y se puso un énfasis especial en la dimensión de liderazgo debido a los resultados encontrados que se detallan a continuación y que fueron la base y guía para el desarrollo del proceso de intervención.

En esta entrega de resultados, se identificaron importantes oportunidades de mejora en la dimensión de liderazgo. El resultado promedio obtenido de dicha dimensión fue de 54 puntos a nivel compañía, lo cual a comparación del benchmark que tenía un puntaje de 53 no estaba desfasado. No obstante, las puntuaciones obtenidas en las áreas comerciales del negocio, de las cuales se espera surjan procesos y proyectos innovadores, revelaron contar con puntajes entre 4 y 34 puntos, lo cual generó discusión y posteriormente la necesidad de intervención en la dimensión, ya que tales puntuaciones revelaban contar con líderes autoritarios, individualistas, poco receptivos y rutinarios, lo cual no favorecía a la creación de entornos innovadores. Esta interpretación de resultados surge del análisis llevado a cabo los ítems asociados a la dimensión de liderazgo en donde se encontró que el porcentaje que marcó las opciones "siempre o frecuentemente" fue el siguiente según cada ítem:

- Sólo el $22 \%$ en "mi jefe directo está abierto a nuevas ideas",

- Sólo el 11\% en "mi jefe directo brinda comentarios o sugerencias constructivas sobre mi trabajo".

- Sólo el $11 \%$ en "mi jefe directo valora los aportes individuales a los proyectos".

- Sólo el $14 \%$ en "en mi área hay personas o líderes que nos estimulan y motivan para innovar en nuestro trabajo". 
Adicionalmente, durante la sesión de discusión de resultados, se identificaron 5 proyectos estratégicos que debían llevarse a cabo entre el último semestre del año 2018 y primer semestre del 2019. De esos 5 proyectos se optó por intervenir en 2 de ellos bajo una metodología de trabajo diferenciada cuyo objetivo sería la participación interdisciplinaria de colaboradores, la estructuración de tiempos de trabajo específicos y la toma de decisiones eficiente, con el fin de agilizar la dinámica de ejecución de los mismos. Para ello se consideró como fase inicial la intervención por medio de capacitaciones en los líderes de primera línea y en todos los de las áreas comerciales implicadas en los proyectos con el fin de dotar a los líderes de competencias y técnicas de trabajo específicas que favorezcan el desarrollo ágil e innovador de los proyectos seleccionados.

\subsubsection{Participantes}

La población total para la evaluación inicial del presente trabajo comprende un total de 436 personas entre hombres y mujeres con edades entre los 24 y 56 años. En este grupo se consideraron desde el nivel más alto de directivos hasta los practicantes que tuviesen más de 3 meses en la compañía. En cuanto a los criterios de exclusión, no se consideró al personal operario de limpieza, de mantenimiento ni de seguridad.

\subsubsection{Técnicas y/o instrumentos de evaluación/diagnóstico}

La herramienta de diagnóstico de Innovación utilizada fue el "Diagnóstico de Innovación C3", la cual se basa en la teoría de creatividad de Amabile. Esta teoría estudia la creatividad bajo la influencia de la cultura, la cual es reconocida como aquel contexto que contiene campos de relaciones e interacciones, artefactos y resultados concretos producto de las interacciones. Por lo tanto, ella afirma que la cultura se convierte en una variable externa a la creatividad que puede impactar directamente en ella (Amabile, 2017).

Esta herramienta ha sido aplicada en cerca de 150 organizaciones desde el 2012, encuestando a más de 30000 personas en Chile, Perú, Bolivia, Argentina, Uruguay y España; y es actualmente la base para el Ranking de Culturas Corporativas Creativas (C3) en Chile y Perú. El C3 es un estudio deductivo y cuantitativo diseñado para corroborar la conexión entre el clima para la creatividad, es decir la cultura, y la innovación. Esta prueba consta de diez factores teóricos y se miden como variables predictivas cuantifi- 
cando su impacto en la percepción de innovación e iniciativas innovadoras de una empresa. Cada dimensión consta de seis a ocho elementos que son evaluados en escala Likert de 4 categorías de respuestas y que están referidos a las condiciones laborales diarias en tres niveles organizacionales: empresa, grupo de trabajo y trabajo personal. La prueba consta de un total de 69 preguntas. En cuanto a las validaciones psicométricas encontradas se detalla que en cuanto a la fiabilidad de la prueba, esta cuenta con un alhpa de cronbach de 0.96. Asimismo, respecto a la validez de la misma, se realizó mediante un análisis factorial confirmatorio que muestra un ajuste positivo de la distribución empírica con la estructura dimensional del modelo, ya que todas las preguntas cuentan con una significancia positiva con sus dimensiones respectivas (Morales, 2015).

Por lo tanto, se puede decir que el modelo C3 utilizado cumplía con las propiedades psicométricas adecuadas para el objetivo de medición que se tenía.

\subsubsection{Procedimientos de evaluación de línea base}

Respecto a la recolección de datos iniciales referidos al diagnóstico, este se llevó a cabo de manera virtual. Sin embargo, cabe resaltar que se debió considerar el envío adjunto de un consentimiento informado que detalle el objetivo de la aplicación de la prueba así como las acciones posteriores a realizar con la recolección de datos. La prueba fue adquirida a un distribuidor oficial, de quien se contrató los servicios de consultoría. En su momento, la aplicación fue dirigida, en conjunto con el consultor externo, y no se llegaron a concretar todos los permisos asociados a la aplicación interna. Es importante mencionar que este será un punto de mejora para las futuras intervenciones en la institución.

En primer lugar, se realizó un plan de comunicación en la compañía por medio de correos y de la intranet indicando que en los próximos días estaría llegando a sus correos corporativos un cuestionario virtual anónimo denominado "Diagnóstico de Innovación C3" desde un dominio externo, el cual evaluaría el estado de innovación en el cual se encontraba la compañía en base a 69 preguntas.

Una vez completado el plan de comunicación, se envió el Cuestionario de Innovación C3, de manera virtual, por medio de un consultor externo, a 436 colaboradores de la compañía. En el correo se colocó un mensaje alentador sobre la importancia de la inserción de la cultura de innovación en la compañía. El plazo máximo para responder el cuestionario era de una semana. Es así que se iba llevando un seguimiento, por medio del 
consultor, acerca del cumplimiento de la evaluación basándonos en los porcentajes de contestación por áreas.

El cuestionario tenía una duración de entre 15 a 20 minutos, por lo cual se tuvo que realizar un seguimiento muy cercano con los líderes de las áreas para que se logre un porcentaje de participación significante, lográndose así un 98\% de contestación.

Luego del cierre de la evaluación, los consultores estuvieron a cargo del procesamiento de resultados y entrega de los mismos pasados 15 días. Para dicha entrega se organizó una reunión de trabajo donde participaron los consultores, el Gerente General, el Gerente de Recursos Humanos y la Business Partner de Recursos Humanos. En esta sesión se comunicaron los resultados por medio de una presentación y los consultores enviaron a Recursos Humanos la matriz en Excel con el procesamiento de los resultados realizado.

\subsection{Implementación}

Para atender al objetivo de la intervención referido a desarrollar las competencias de Escucha Activa y Trabajo Colaborativo, propias del liderazgo servidor, se planteó el diseño de un programa formativo ejecutado bajo la modalidad de Taller. 
Tabla 4.1

Matriz organizativa de la implementación de los talleres

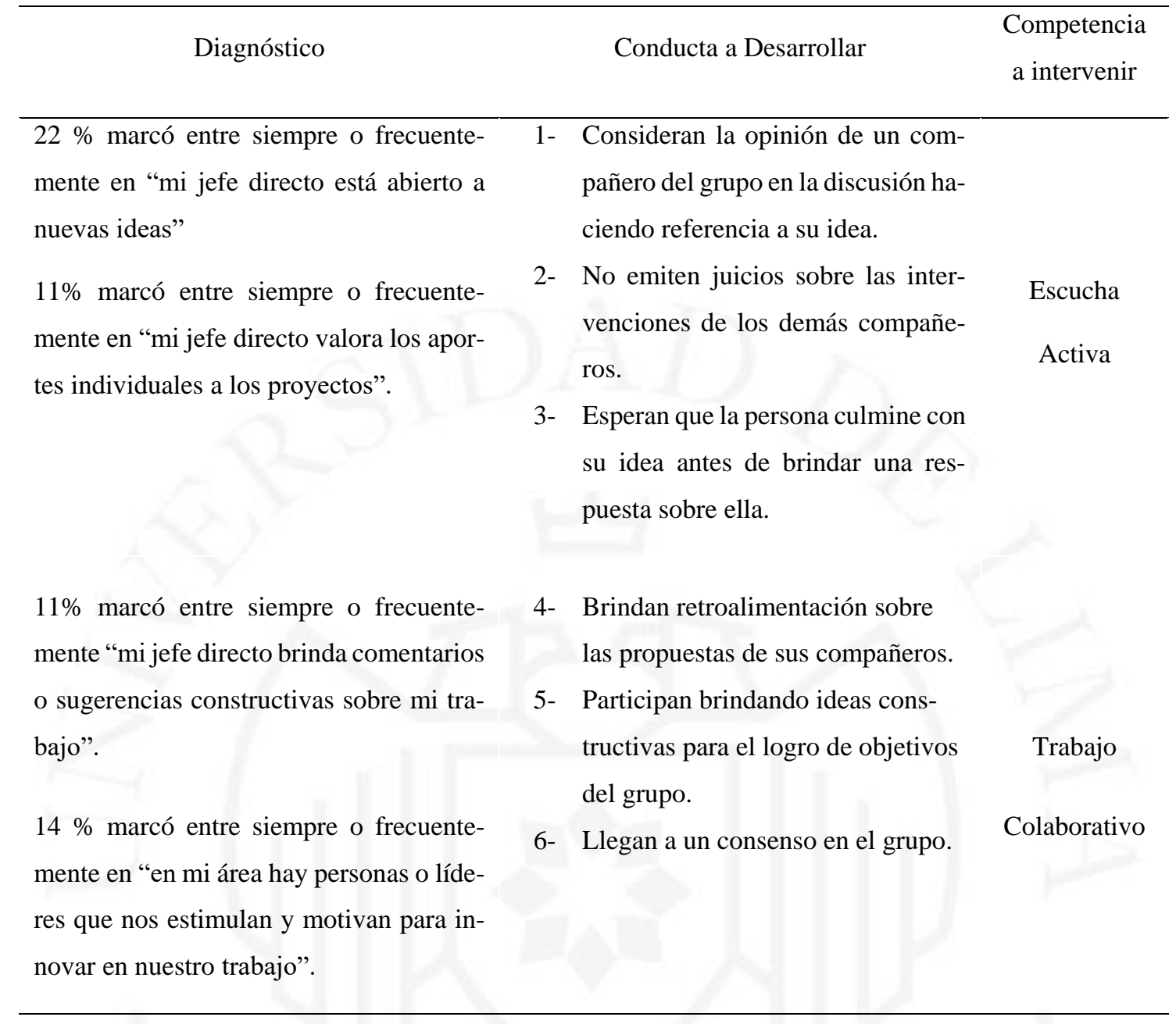

La intervención a nivel de liderazgo se llevó a cabo por medio del diseño y ejecución de 2 talleres específicos para los líderes de las áreas comerciales. Dichos talleres abordaron la problemática identificada en el diagnóstico de cultura de innovación, la cual reveló la necesidad de desarrollar las 2 competencias a las cuales se hacen mención. Estos talleres fueron desarrollados en 2 sesiones cada uno y los invitados considerados fueron los mismos para ambos. Para el cumplimiento del presente trabajo se ha fraccionado el taller incidiendo en aquellas actividades relacionadas específicamente a las competencias a desarrollar y la totalidad del taller se presentará en la sección de apéndices. 


\subsubsection{Participantes}

De la población total encuestada, 146 corresponde a líderes entre coordinadores, jefes, directores y gerentes. Se incluyeron a 36 líderes de los cuales 8 eran gerentes, 4 directores, 15 jefes y 9 coordinadores. Los gerentes eran los líderes de área de primera línea y en el caso de los demás participantes, todos pertenecían a las áreas comerciales. Estos participantes fueron seleccionados teniendo como premisas que fueran líderes pertenecientes a las áreas comerciales, con lo cual se seleccionó a la totalidad de los de dichas áreas, y adicionalmente, la gerencia general solicitó incorporar a todos sus reportes directos. Por lo contrario, se excluyeron a aquellos colaboradores que no tenían posiciones de supervisión de equipo y no se consideraron a aquellos líderes de las áreas de soporte.

\subsubsection{Instrumentos o herramientas de implementación/intervención}

Para la intervención se llevaron a cabo dos talleres específicos, los cuales fueron desarrollados en conjunto con el consultor que estuvo a cargo de la aplicación inicial del diagnóstico de innovación. Para ello, se tuvo como base el Modelo Instruccional de la 4ta generación el cual se apoya en el constructivismo y tal como lo vimos en capítulos anteriores, se centra en el proceso de aprendizaje enfocado en el alumno y generando una participación activa en todo momento para lograr que sean los participantes los dueños y constructores de su propio aprendizaje.

Para el desarrollo de la matriz instruccional, se consideraron los siguientes campos: etapa, tarea o fase, objetivo de aprendizaje, actividades, materiales y recursos, tiempo e instrumento de evaluación, además de evidenciar el resultado de aprendizaje, módulo o taller y número de sesión, sin embargo, en esta sección presentaremos aquellos campos de mayor relevancia para nuestro objetivo. 
Tabla 4.2

Matriz de Diseño Instruccional Taller 1

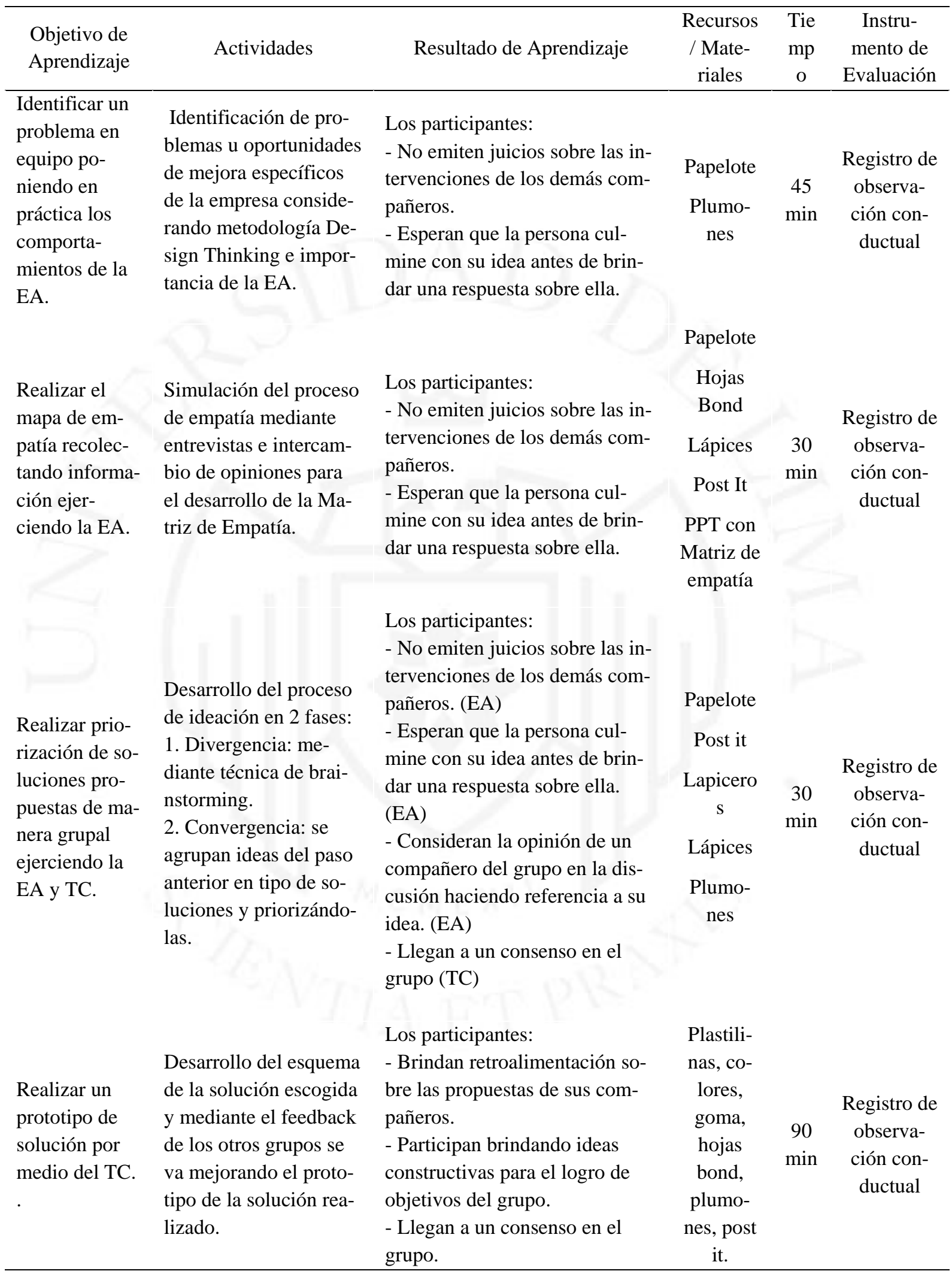


Tabla 4.3

Matriz de Diseño Instruccional Taller 2

\begin{tabular}{|c|c|c|c|c|c|}
\hline $\begin{array}{l}\text { Objetivo de } \\
\text { Aprendizaje }\end{array}$ & Actividades & Resultado de Aprendizaje & $\begin{array}{c}\text { Recursos } \\
\text { / Mate- } \\
\text { riales }\end{array}$ & $\begin{array}{c}\text { Tie } \\
\text { mp } \\
\text { o }\end{array}$ & $\begin{array}{c}\text { Instru- } \\
\text { mento de } \\
\text { Evaluación }\end{array}$ \\
\hline $\begin{array}{l}\text { Realizar un } \\
\text { Product Bak- } \\
\text { clog por } \\
\text { equipo consi- } \\
\text { derando el TC } \\
\text { y la EA para la } \\
\text { priorización. }\end{array}$ & $\begin{array}{l}\text { Docente indica cómo } \\
\text { definir las historias de } \\
\text { los usuarios en un } \\
\text { "Product Backlog" y } \\
\text { cómo organizarlo. } \\
\text { Participantes desarro- } \\
\text { llan su Product Ba- } \\
\text { cklog por equipos. }\end{array}$ & $\begin{array}{l}\text { Los participantes: } \\
\text { - Consideran la opinión de un } \\
\text { compañero del grupo en la dis- } \\
\text { cusión haciendo referencia a su } \\
\text { idea. (EA) } \\
\text { - Participan brindando ideas } \\
\text { constructivas para el logro de } \\
\text { objetivos del grupo. (TC) } \\
\text { - Llegan a un consenso en el } \\
\text { grupo (TC) }\end{array}$ & Papelote & $\begin{array}{c}30 \\
\min \end{array}$ & $\begin{array}{c}\text { Registro de } \\
\text { observa- } \\
\text { ción con- } \\
\text { ductual }\end{array}$ \\
\hline $\begin{array}{l}\text { Concretizar un } \\
\text { punto de par- } \\
\text { tida de los ob- } \\
\text { jetivos de los } \\
\text { proyectos. }\end{array}$ & $\begin{array}{l}\text { Representación de los } \\
\text { resultados de sus sprint } \\
\text { a través de dibujos o } \\
\text { esquemas para lograr } \\
\text { un Storyboard y recep- } \\
\text { ción de los feedbacks } \\
\text { de los otros equipos in- } \\
\text { centivando la EA y el } \\
\text { TC. }\end{array}$ & $\begin{array}{l}\text { Los participantes: } \\
\text { - Esperan que la persona cul- } \\
\text { mine con su idea antes de brin- } \\
\text { dar una respuesta sobre ella. } \\
\text { (EA) } \\
\text { - Brindan retroalimentación so- } \\
\text { bre las propuestas de sus com- } \\
\text { pañeros. (TC). } \\
\text { - Participan brindando ideas } \\
\text { constructivas para el logro de } \\
\text { objetivos del grupo. (TC) }\end{array}$ & $\begin{array}{l}\text { hojas } \\
\text { bond, co- } \\
\text { lores, la- } \\
\text { pices y } \\
\text { papelote }\end{array}$ & $\begin{array}{c}75 \\
\min \end{array}$ & $\begin{array}{l}\text { Registro de } \\
\text { observa- } \\
\text { ción con- } \\
\text { ductual }\end{array}$ \\
\hline
\end{tabular}

\subsubsection{Procedimiento de implementación}

En línea con el objetivo de desarrollar las competencias de Escucha Activa y Trabajo Colaborativo del líder servidor, dentro de un marco de trasformación hacia una Cultura de Innovación, se llevaron a cabo diversas actividades como parte de dos talleres según como se describe a continuación:

\section{Para el desarrollo de solo Escucha Activa:}

- Dinámica de Identificación de Problemas: Mediante el diálogo y discusión sobre los problemas que existen en el área y basándose en la metodología Design Thinking, los participantes obtienen una comprensión adecuada de la realidad, lo cual les permitió el verdadero problema a abordar llevándolos a evidenciar los siguientes comportamientos de la EA: no emitir juicios sobre las intervenciones de los demás compañeros 
y esperar que la persona culmine con su idea antes de brindar una respuesta sobre ella.

- Definir un mapa de empatía: Mediante la interacción en sesiones o entrevistas, con los usuarios del problema definido en el paso anterior, donde la escucha activa toma un papel muy importante, se logró obtener la información necesaria que permitiera comprender cuál es la posición de los involucrados en el problema y qué soluciones se podrían desarrollar de manera creativa evidenciando nuevamente que los participantes no emiten juicios sobre las intervenciones de los demás compañeros y esperan que la persona culmine con su idea antes de brindar una respuesta sobre ella.

Para desarrollo de Escucha Activa y Trabajo Colaborativo:

- Dinámica de Brainstorming y Convergencia de Ideas: Ahora con un problema bien definido y con una comprensión adecuada de la posición de los involucrados en el problema se procede a realizar una sesión de Brainstormig (proceso divergente) en la cual, mediante la Escucha Activa y el Trabajo Colaborativo, se agrupan todas las ideas por tipo de solución, sin descartar ninguna. Esto dará paso a la siguiente sesión (proceso convergente) en la cual, mediante un facilitador y el consenso en equipo se va descartando las ideas que no son coherentes con el problema y el mapa de empatía definido.

- Dinámica de desarrollo de un Product Backlog: una vez obtenido el problema y mapa de empatía se procede a realizar un ejercicio de clasificación y priorización, para lo cual se incentivan los siguientes comportamientos asociados a la Escucha Activa y al Trabajo Colaborativo: que los participantes consideren la opinión de un compañero del grupo en la discusión haciendo referencia a su idea (EA), participen brindando ideas constructivas para el logro de objetivos del grupo (TC) y lleguen a un consenso en el grupo (TC).

- Dinámica para concretizar un punto de partida de los objetivos de los proyectos: se solicita a los participantes que representen sus resultados a través de dibujos o esquemas para lograr un Storyboard, para lo cual se incentivan los siguientes comportamientos asociados a la EA y TC: que los participantes esperen que la persona culmine con su idea antes de brindar una respuesta sobre ella. (EA), brinden retroalimentación sobre las propuestas de sus compañeros (TC) y participen brindando ideas constructivas para el logro de objetivos del grupo (TC). 
Para desarrollo de Trabajo Colaborativo

- $\quad$ Elaboración de Prototipo: los participantes desarrollan el esquema de la solución escogida y mediante el feedback de los otros grupos se busca que mejoren el prototipo de la solución realizado, para lo cual se espera que entre los involucrados se brinden retroalimentación sobre sus propuestas, participen brindando ideas constructivas para el logro de objetivos del grupo y lleguen a un consenso en el grupo, evidenciando así los tres comportamientos asociados al TC.

Todas estas actividades formaron parte de los Talleres de Cambio de Mindset e Introducción al Design Thinking y de Metodologías Agiles los cuales tuvieron una duración de 4 sesiones con un total de 20 horas entre los meses de setiembre y noviembre del año 2018.

Como parte de la estrategia para conseguir desarrollar las capacidades mencionadas, fue contratar a un docente especialista en la movilización de conductas quien tenía como profesión la de psicólogo y su expertise se centraba en la consultoría sobre liderazgo mediante la ejecución de talleres. En conjunto con él, se establecieron grupos de trabajos en los cuales primaba la diversidad de perfiles, ya que se escogieron integrantes de diferentes áreas para cada equipo, lo cual estimuló a que los participantes estuvieran más atentos a las diferentes intervenciones en sus equipos y sobre todo a la apertura de nuevas formas de pensar reforzando la necesidad de un trabajo colaborativo para conseguir resultados innovadores. Los equipos se distribuyeron en mesas redondas de 6 integrantes para propiciar el diálogo cara a cara. En cada equipo había un facilitador, el cual ayudaba a que la discusión progresara de manera ordenada y cumpliendo los tiempos para cada actividad.

\subsection{Evaluación de proceso}

La evaluación del proceso de intervención se realizó durante las actividades descritas anteriormente haciendo uso de un registro de observación de conductas. Cabe resaltar que la fase inicial del proceso de diagnóstico empezó con la aplicación del Diagnóstico de Innovación C3 que guío ésta intervención formativa en los líderes y en base a ello se definieron los siguientes resultados de aprendizaje de acuerdo a las competencias de EA y TC:

Escucha Activa (EA): 
- Consideran la opinión de un compañero del grupo en la discusión haciendo referencia a su idea.

- No emiten juicios sobre las intervenciones de los demás compañeros.

- Esperan que la persona culmine con su idea antes de brindar una respuesta sobre ella.

Trabajo Colaborativo (TC):

- Llegan a un consenso en el grupo

- Brindan retroalimentación sobre las propuestas de sus compañeros

- Participan brindando ideas constructivas para el logro de objetivos del grupo

A partir de la definición de tales conductas se obtuvieron resultados favorables pero que fueron incrementando gradualmente en su favorabilidad. En la primera actividad se logró que el $50 \%$ de participantes no emita juicios sobre las intervenciones de los demás compañeros y que el 50\% espere que la persona culmine con su idea antes de brindar una respuesta sobre ella. En la segunda actividad, el 100\% de participantes logró no emitir juicios sobre las intervenciones de los demás compañeros y el 100\% esperó que la persona culmine con su idea antes de brindar una respuesta sobre ella. En la tercera actividad, el 100\% de participantes no emitió juicios sobre las intervenciones de los demás compañeros (EA), el 100\% esperó que la persona culmine con su idea antes de brindar una respuesta sobre ella (EA), el 100\% consideró la opinión de un compañero del grupo en la discusión haciendo referencia a su idea. (EA), pero sólo el 67\% logró llegar a un consenso en el grupo (TC). En la cuarta actividad, el 100\% brindó retroalimentación sobre las propuestas de sus compañeros, el 100\% participó brindando ideas constructivas para el logro de objetivos del grupo y el 100\% llegó a un consenso en el grupo. Durante la quinta actividad, el 100\% de participantes consideró la opinión de un compañero del grupo en la discusión haciendo referencia a su idea (EA), el 100\% participó brindando ideas constructivas para el logro de objetivos del grupo y el 100\% llegó a un consenso en el grupo (TC). Finalmente, en la última actividad, el 100\% de participantes esperó que la persona culmine con su idea antes de brindar una respuesta sobre ella (EA), el 100\% brindó retroalimentación sobre las propuestas de sus compañeros (TC) y el 84\% participó brindando ideas constructivas para el logro de objetivos del grupo (TC).

A continuación detallamos los participantes que estuvieron a lo largo del proceso, la técnica de evaluación utilizada y el procedimiento que guio la evaluación del proceso. 


\subsubsection{Participantes}

De los 36 participantes considerados en la intervención inicialmente, se llegó a completar todo el proceso con 34 , ya que 2 de ellos no pudieron asistir a los dos talleres planteados. Uno de los ausentes fue uno de los 8 gerentes y el otro participante que abandonó el proceso fue un coordinador. Ambos tuvieron percances laborales que no les permitieron disponer del tiempo para asistir a la totalidad de talleres.

\subsubsection{Técnicas y/o instrumentos de evaluación/diagnóstico}

La técnica de evaluación considerada a lo largo de la ejecución y desarrollo de los dos talleres fue el registro de observación de conductas, el cual fue utilizado durante las 6 actividades anteriormente descritas. Estos registros de observación conductual fueron definidos teniendo como base el objetivo de cada actividad y el resultado de aprendizaje a conseguir.

\subsubsection{Procedimiento de evaluación de proceso}

La recopilación de la información y resultados parciales de la intervención, se llevó a cabo en cada una de las sesiones de capacitación. Los resultados progresivos del aprendizaje fueron recopilados durante o al finalizar las actividades descritas en la matriz de diseño instruccional.

En primer lugar, se realizó un registro de observación de comportamientos asociados a la escucha activa durante la conversación grupal de cada equipo para el logro de la identificación del problema. Para ello, se consideraron los siguientes comportamientos observables: no emitir juicios sobre las intervenciones de los demás compañeros y esperar que la persona culmine con su idea antes de brindar una respuesta sobre ella

En segunda lugar, se realizó una Matriz de Empatía para asegurar la recolección de datos efectiva considerando la observación de comportamientos asociados a la escucha activa.

En tercer lugar, se procedió a realizar la priorización de soluciones en un papelote, por medio del cual se evaluó la habilidad de escucha activa así como la de trabajar de manera colaborativa para llegar a consensos. 
En cuarto lugar, se ejecutó un prototipo, para lo cual debían considerar la retroalimentación del otro equipo, por lo tanto, se podía evaluar los comportamientos asociados al trabajo colaborativo.

En cuanto al segundo taller, la recopilación de información evaluativa inició con un registro de observación de los comportamientos básicos asociados a la escucha activa y trabajo colaborativo durante la realización del Product Backlog.

Finalmente, se volvió a realizar un siguiente registro de observación de conductas asociadas a la escucha activa y trabajo colaborativo, pero esta vez durante la generación del Storyboard del proyecto. En esta oportunidad se identificaron conductas tales como: la aceptación de opiniones diversas, no juzgar las opiniones diferentes, apertura ante posturas opuestas, comentarios constructivos dentro del equipo y retroalimentación constante. 


\section{CAPÍTULO V: RESULTADOS}

\subsection{Resultados descriptivos cuantitativos}

A continuación se presentan los resultados obtenidos en base a los dos talleres llevados a cabo entre los meses de setiembre y noviembre del 2018 con respecto a la adquisición de las conductas propias de las competencias objetivo. Para ello, se describirán los resultados alcanzados durante el proceso de intervención evidenciando el desarrollo de los comportamientos relacionados con la adopción de las 2 competencias del líder servidor seleccionadas a desarrollar en los líderes: trabajo colaborativo y escucha activa en busca de la generación de una cultura de innovación en las áreas comerciales.

A continuación, se muestra una tabla con los resultados obtenidos: 
Tabla 5.1

\section{Recopilación de resultados del taller 1 de Cambio de Mindset e Introducción al Design Thinking}

\begin{tabular}{|c|c|c|}
\hline $\begin{array}{c}\text { Herra- } \\
\text { mienta de } \\
\text { medición }\end{array}$ & Objetivo planteado & Resultado obtenido \\
\hline $\begin{array}{l}\text { Registro de } \\
\text { observación } \\
\text { de conducta }\end{array}$ & $\begin{array}{l}\text { El } 100 \% \text { de los participantes evidencian los si- } \\
\text { guientes comportamientos: } \\
\text { - No emitir juicios sobre las intervenciones de los } \\
\text { demás compañeros } \\
\text { - Esperar que la persona culmine con su idea an- } \\
\text { tes de brindar una respuesta sobre ella }\end{array}$ & $\begin{array}{l}\text { - } 50 \% \text { evidenció no emitir juicios so- } \\
\text { bre las intervenciones de los demás } \\
\text { compañeros. } \\
\text { - } 50 \% \text { evidenció esperar que la per- } \\
\text { sona culmine con su idea antes de } \\
\text { brindar una respuesta sobre ella }\end{array}$ \\
\hline $\begin{array}{l}\text { Registro de } \\
\text { observación } \\
\text { de conducta }\end{array}$ & $\begin{array}{l}\text { Los } 6 \text { grupos realizan la Matriz de Empatía evi- } \\
\text { denciando los siguientes comportamientos: } \\
\text { - No emitir juicios sobre las intervenciones de los } \\
\text { demás compañeros } \\
\text { - Esperar que la persona culmine con su idea an- } \\
\text { tes de brindar una respuesta sobre ella }\end{array}$ & $\begin{array}{l}\text { - } 6 \text { grupos evidenció no emitir juicios } \\
\text { sobre las intervenciones de los de- } \\
\text { más compañeros. } \\
\text { - } 6 \text { grupos evidenció esperar que la } \\
\text { persona culmine con su idea antes de } \\
\text { brindar una respuesta sobre ella }\end{array}$ \\
\hline $\begin{array}{l}\text { Registro de } \\
\text { observación } \\
\text { de conducta }\end{array}$ & $\begin{array}{l}\text { Los } 6 \text { grupos realizan la priorización de soluciones } \\
\text { evidenciando: } \\
\text { - No emitir juicios sobre las intervenciones de los } \\
\text { demás compañeros (EA) } \\
\text { - Esperar que la persona culmine con su idea an- } \\
\text { tes de brindar una respuesta sobre ella (EA) } \\
\text { - Considerar la opinión de un compañero del } \\
\text { grupo en la discusión haciendo referencia a su } \\
\text { idea. (EA) } \\
\text { - Llegar a un consenso en el grupo (TC). }\end{array}$ & $\begin{array}{l}\text { - } 6 \text { grupos no emitió juicios sobre las } \\
\text { intervenciones de los demás compa- } \\
\text { ñeros (EA), } \\
\text { - } 6 \text { grupos esperaron que la persona } \\
\text { culmine con su idea antes de brindar } \\
\text { una respuesta sobre ella (EA). } \\
\text { - } 6 \text { grupos consideró la opinión de un } \\
\text { compañero del grupo en la discusión } \\
\text { haciendo referencia a su idea. (EA) } \\
\text { - } 4 \text { grupos lograron llegar a un con- } \\
\text { senso en el grupo (TC). }\end{array}$ \\
\hline $\begin{array}{l}\text { Registro de } \\
\text { observación } \\
\text { de conducta }\end{array}$ & $\begin{array}{l}\text { Los } 6 \text { grupos realizan el prototipo y evidencian: } \\
\text { - Brindar retroalimentación sobre las propuestas } \\
\text { de sus compañeros } \\
\text { - Participar brindando ideas constructivas para el } \\
\text { logro de objetivos del grupo } \\
\text { - Llegar a un consenso en el grupo. }\end{array}$ & $\begin{array}{l}\text { - } 6 \text { grupos brindó retroalimentación } \\
\text { sobre las propuestas de sus compa- } \\
\text { ñeros } \\
\text { - } 6 \text { grupo participaron brindando ideas } \\
\text { constructivas para el logro de objeti- } \\
\text { vos del grupo. } \\
\text { - } 6 \text { grupos llegaron a un consenso }\end{array}$ \\
\hline $\begin{array}{l}\text { Registro de } \\
\text { observación } \\
\text { de conducta }\end{array}$ & $\begin{array}{l}\text { Los } 6 \text { grupos realizan el product backlog eviden- } \\
\text { ciando: } \\
\text { - } 6 \text { grupos consideran la opinión de un compa- } \\
\text { ñero del grupo en la discusión haciendo refe- } \\
\text { rencia a su idea (EA) } \\
\text { - } 6 \text { grupos participan brindando ideas construc- } \\
\text { tivas para el logro de objetivos del grupo. } \\
\text { - } 6 \text { grupos llegan a un consenso en el grupo } \\
\text { (TC). }\end{array}$ & $\begin{array}{l}\text { - } 6 \text { grupos consideraron la opinión } \\
\text { de un compañero del grupo en la } \\
\text { discusión haciendo referencia a su } \\
\text { idea (EA) } \\
\text { - } 6 \text { grupos participaron brindando } \\
\text { ideas constructivas para el logro } \\
\text { de objetivos del grupo } \\
\text { - } 6 \text { grupos llegaron a un consenso } \\
\text { en el grupo (TC). }\end{array}$ \\
\hline $\begin{array}{l}\text { Registro de } \\
\text { observación } \\
\text { de conducta }\end{array}$ & $\begin{array}{l}6 \text { grupos esperan que la persona culmine con } \\
\text { su idea antes de brindar una respuesta sobre } \\
\text { ella (EA). } \\
6 \text { grupos brindan retroalimentación sobre las } \\
\text { - } \\
\text { propuestas de sus compañeros. } \\
6 \text { grupos participan brindando ideas construc- } \\
\text { tivas para el logro de objetivos del grupo } \\
\text { (TC). }\end{array}$ & $\begin{array}{l}6 \text { grupos esperan que la persona } \\
\text { culmine con su idea antes de brin- } \\
\text { dar una respuesta sobre ella (EA). } \\
6 \text { grupos brindan retroalimenta- } \\
\text { ción sobre las propuestas de sus } \\
\text { compañeros. } \\
5 \text { grupos participan brindando } \\
\text { ideas constructivas para el logro } \\
\text { de objetivos del grupo (TC). }\end{array}$ \\
\hline
\end{tabular}


Para el registro de observación de comportamientos asociados a la escucha activa se consideraron los comportamientos observables de no emitir juicios sobre las intervenciones de los demás compañeros y esperar que la persona culmine con su idea antes de brindar una respuesta sobre ella. En este primer registro de observación, hubo sólo un $50 \%$ de participantes que evidenciaban los comportamientos descritos.

Respecto a la realización de la Matriz de Empatía, los 6 grupos pudieron concluir con dicha matriz en el tiempo establecido y con la evidencia de las conductas asociadas a la EA.

Durante la actividad de priorización de soluciones realizada, se evaluó la habilidad de escucha activa y la de trabajar de manera colaborativa. De los 6 grupos, 2 de ellos no lograron evidenciar la conducta de llevar a un consenso. Por lo tanto, se entiende que solo el $67 \%$ de los participantes logró llevar a cabo esta conducta, mientras que las otras conductas evidenciadas en la actividad fueron logradas al 100\%.

Para la ejecución del prototipo, el 100\% de los equipos brindó retroalimentación sobre las propuestas de sus compañeros, participó brindando ideas constructivas para el logro de objetivos del grupo y llegó a un consenso en el grupo.

Durante la realización del Product Backlog, los principales comportamientos identificados fueron: considerar la opinión de un compañero del grupo en la discusión haciendo referencia a su idea (EA), participar brindando ideas constructivas para el logro de objetivos del grupo y llegar a un consenso en el grupo (TC). Los 6 equipos reflejaron adoptar los 3 comportamientos durante la realización y logro del Product Backlog.

En el último registro de observación de conductas asociadas a la escucha activa y trabajo colaborativo, se identificó que 6 grupos lograron esperar que la persona culmine con su idea antes de brindar una respuesta sobre ella (EA), 6 grupos brindaron retroalimentación sobre las propuestas de sus compañeros, sin embargo sólo 5 grupos participaron brindando ideas constructivas para el logro de objetivos del grupo (TC), con lo cual el $84 \%$ de participante logró reflejar este último comportamiento en esta actividad.

Finalmente es importante mencionar que la organización propició el desarrollo de las competencias de EA y TC mediante las siguientes acciones que se describen a continuación: i) la creación de un "Comité Interdisciplinario" con periodicidad quincenal para la toma de decisiones oportunas sobre los proyectos en curso y logro de los objetivos en 
los tiempos propuestos. Además, ii) se fomentó la participación activa de todas las categorías de colaboradores para que expusieran sus ideas y puntos de vista sobre los procesos que cada uno trabajaba en su día a día y que impactaban directamente en los proyectos compañía. Finalmente, iii) se propició la escucha activa de todos los colaboradores por medio de la práctica del "Daily meeting" en las áreas, en donde se impulsaba la participación de aquellos colaboradores que quisieran comentar los avances e ideas de los procesos o proyectos en los cuales estaban involucrados, lo cual permitió la toma de decisiones oportuna para un mayor avance de los procesos y proyectos en donde estaban involucrados los colaboradores, así como el relevamiento de nuevas ideas y opiniones de los colaboradores por parte de los líderes sobre los diferentes proyectos que cada uno mencionaba.

\subsection{Resultados interpretativos}

Luego de los resultados obtenidos durante las actividades del primer taller desarrollado, se evidenció que en 3 de las 6 actividades realizadas los participantes evidenciaron el $100 \%$ de las conductas objetivo. En las otras 3 actividades se pudieron identificar algunas dificultades específicamente en las siguientes conductas: llegar a un consenso y participar brindando ideas constructivas para el logro de objetivos del grupo, las cuales corresponden a comportamientos de la competencia de Trabajo Colaborativo.

Por lo tanto, se puede ver que se obtuvieron resultados favorables en cuanto al desarrollo de las competencias, pero haciendo énfasis que se obtuvieron mejores resultados en el desarrollo de la competencia de Escucha Activa. 


\section{CONCLUSIONES}

- Con respecto al objetivo propuesto, se alcanzaron resultados favorables en el desarrollo de las conductas asociadas a la Escucha Activa, ya que se logró evidenciar el $100 \%$ de los comportamientos durante las actividades realizadas.

- Los comportamientos asociadas al trabajo colaborativo también fueron debidamente evidenciados a lo largo de las actividades, sin embargo, se identificaron dificultades a nivel de 2 conductas en un grupo de participantes, por lo cual será necesario seguir reforzando las conductas de llegar a consensos grupales y de participar brindando ideas constructivas para el logro de objetivos del grupo.

- Los espacios de direccionamiento de equipos hacia una cultura de innovación fueron fomentados por dos prácticas puntuales donde se evidenció el desarrollo de la EA y del TC: la creación de comités interdisciplinarios y la ejecución de daily meetings. Acciones que fueron posteriormente promovidas por la organización con el fin de seguir fomentando el desarrollo de ambas competencias. Ambos espacios beneficiaron el impulso de procesos y proyectos orientados a impactar en el reto de innovación identificado en la compañía respecto al nuevo canal de venta digital. 


\section{RECOMENDACIONES}

- Se sugiere que para el logro del desarrollo del 100\% de las competencias se consideren realizar más talleres con dinámicas que favorezcan la práctica y ejecución de los comportamientos asociados al trabajo colaborativo, el cual no logró ser desarrollado en su totalidad en el $100 \%$ de participantes.

- Se recalca la importancia de la intervención posterior de la organización para la adopción sostenible de ciertas prácticas entorno al direccionamiento de un equipo, ya que generando espacios de refuerzo de las competencias estas pueden ser mejoradas y establecidas formalmente para toda la compañía, generando así un mayor impacto a nivel cultural.

- Finalmente, cabe señalar que hubiese sido óptimo contar con la aplicación final del "Diagnóstico de Innovación C3" para contar con mayores precisiones respecto a los campos de acción aún pendientes de desarrollar y aquellos que sólo es necesario seguir reforzando. 


\section{REFERENCIAS}

¿Como influye la transformación cultural en una empresa? (22 de julio de 2019). Gestión. Recuperado de https://gestion.pe/videos/influye-transformacion-culturalempresa-273877-noticia/

Amabile, T. (1996). Creatividad e Innovación en las Organizaciones. Harvard Business School, 1-13. Recuperado de Virtual Experience: https://virtualexperience.cl/wpcontent/uploads/2017/12/Creatividad-e-Innovaci\%c3\%b3n-en-las-

Organizaciones.pdf

Amabile, T. (2017). In Pursuit of Everyday Creativity. The Journal of Creative Behavior, 51, 335-337. doi:10.1002/jocb.200

Belloch, C. (2012). Diseño Instruccional. Recuperado de UDG Virtual: http://www.uv.es/ bellochc/pedagogia/EVA4.pdf

Bellomusto, R. y Esquembre, J. (2014). Innovación y gestión estratégica de proyectos. Buenos Aires: Cengage Learning.

Brugioni, M. (7 de abril de 2018). Los otros y yo: el líder servidor. Recuperado de Blog Master de Salud Pública y Gestión Sanitaria: https://www.easp.es/blogmsp/2018/04/07/los-otros-y-yo/

CAPEVEDI. (s.f.). ¿Quiénes Somos? Recuperado de CAPEVEDI Cámara Peruana de Venta Directa: http://capevedi.com/

Cifuentes, L. M. y Londoño, M. E. (2017). Rasgos Identificativos que promueven la Cultura de la Innovación en las organizaciones. Revista Interamericana de Psicología Ocupacional, 36(1), 36-48. doi:10.21772/ripo.v36n1a03

Contreras, T. F. (2016). Liderazgo: antecentes, tendencias y perspectivas de desarrollo. Bogotá: Universidad del Rosario. Recuperado de https://ebookcentral-proquestcom.ezproxy.ulima.edu.pe

COPECOH. (s.f.). Quiénes Somos. Recuperado de El Gremio Peruano de Cosmética e Higiene: http://copecoh.org/index.php/quienes-somos/

Cornell University, INSEAD, WIPO. (2019). Indice Mundial de Innovación 2019 Una vida sana para todos: el futuro de la innovación médica. Recuperado de Organización Mundial de la Propiedad Intelectual: https://www.wipo.int/publications/es/details.jsp?id=4435\&plang=ES

Ferrer, R. (2018). El comportamiento organizacional y su relación en los procesos de innovación tecnológica. Revista de Investigación en Ciencias Sociales y Humanidades, 5(2), 169-178. doi:http://dx.doi.org/10.30545/academo.2018.juldic. 9

Framil, L. y Ovanessoff, A. (17 de junio de 2016). ¿Qué pueden hacer los líderes de América Latina para que la región sea más innovadora? Recuperado de World Economic Forum: https://es.weforum.org/agenda/2016/06/que-pueden-hacerlos-lideres-de-america-latina-para-que-la-region-sea-mas-innovadora-addfd97fff68-460a-9edc-3b8daad245f5/

Gaviria, A., Ratti, D., Quiroga, G., Ontaneda, E., y Galdós, G. (2014). Estilos de toma de decisión de líderes en Perú. Lima: Universidad Peruana de Ciencias Aplicadas .

Greenleaf, R. (1977). The Servant as Leader. Indianapolis: Paulist Press. Recuperado de http://www.ediguys.net/Robert_K_Greenleaf_The_Servant_as_Leader.pdf 
Haro, F., Córdova, N., \& Alvarado, M. (2017). Importancia de la innovación y su ejecución en la estrategia empresarial. Innova Research Journal, 2(5), 88-105. doi:https://doi.org/10.33890/innova.v2.n5.2017.167

Hermosilla, D., Amutio, A., Da Costa, S., y Páez, D. (2016). El Liderazgo transformacional en las organizaciones: variables, mediadoras y consecuencias a largo plazo. Journal of Work and Organizational Psychology, 135-143.

Inga, C. (05 de setiembre de 2019). Sector de cosmética e higiene personal reajusta proyección de crecimiento. Recuperado de El Comercio: https://elcomercio.pe/economia/dia-1/sector-cosmetica-e-higiene-personalreajusta-proyeccion-crecimiento-avon-unique-noticia-672850-noticia/

Kelley, T. y Littman, J. (2016). Las diez caras de la innovación: Estrategias para una creatividad excelente. Barcelona: Paidos.

Kotter, J. (2007). Liderar el cambio por qué fracasan los intentos de transformación. Harvard Business Review, 83-90.

López, C. (2014). Factores psicosociales que caracterizan a los equipos innovadores: Un modelo multinivel de evaluación. Revista Interamericana de Psicología Ocupacional, 11(1), 11-30. Recuperado de http://fresno.ulima.edu.pe/ss_bd00102.nsf/RecursoReferido?OpenForm\&id=PR OQUEST-41716\&url=/docview/2100186163? accountid=45277

López, M. (2017). Proyecto de Consultoría de Recursos Humanos (Tesis de maestría). Recuperado de https://repositorio.comillas.edu/xmlui/handle/11531/24009

Maxwell, J. C. (1993). Desarrolle el líder que está en usted. Nashville, EEUU: Thomas Nelson Publishers.

Ministerio de Salud. (s.f.). ¿QUÉ ES LA DIGEMID? Recuperado de Digemid - Minsa: http://www.digemid.minsa.gob.pe/Main.asp?Seccion=39

Molina, C. (16 de abril de 2019). Estudio de Mercado. El mercado de cosmética e higiene personal en Perú. Recuperado de ICEX España Exportación e Inversiones: https://www.icex.es/icex/es/navegacion-principal/todos-nuestrosservicios/informacion-de-mercados/estudios-de-mercados-y-otros-documentosde-comercio-exterior/DOC2019819188.html

Morales, J. (2015). Measuring and managing creativity for innovation. (Tesis de maestría). The London School of Economics and Political Science.

Muinelo, A. (4 de junio de 2018). La Cultura de la innovación. Recuperado de IWS Consultores: http://www.iwsconsultores.com/la-cultura-la-innovacion/

Naranjo-Valencia, J. C. y Calderón-Hernández, G. (13 de febrero de 2015). Construyendo una cultura de innovación. Una propuesta de transformación cultural. Estudios Gerenciales(31), 223-236. Recuperado de Science Direct. Jornals \& Books: https://www.sciencedirect.com/science/article/pii/S0123592315000054

Novella, R., Alvarado, A., Rosas, D. y González-Velosa, C. (Marzo de 2019). Identificación, causas y consecuencias de la brecha de habilidades en Perú . Recuperado de IDB Improving lives: https://publications.iadb.org/publications/spanish/document/Identificaci\%C3\%B 3n_causas_y_consecuencias_de_la_brecha_de_habilidades_de_Per\%C3\%BA.p df

OCDE y Eurostat. (2006). Manual de Oslo. Guía para la recogida e interpretación de datos sobre inovación. Recuperado de UNED: http://portal.uned.es/portal/page?_pageid=93,23280929\&_dad=portal\&_schema $=$ PORTAL 
Pantoja, M. y Suárez, F. (10 de mayo de 2017). El concepto de liderazgo en la historia ante la administración sistémica. Recuperado de UANL: http://revistainnovaciones.uanl.mx/index.php/revin/article/view/263/235

Rincón, L. (2014). Marco Referencial del Diseño Instruccional bajo enfoque constructivista. Recuperado de Academia: https://www.academia.edu/6968343/Dise\%C3\%B1o_Instruccional_Constructivi sta._Etapa1._Marco_Referencial

Rivera, L. (2016). Liderazgo y Cultura Organizacional en Latinoamérica. (Tesis para optar el título profesional de Licenciado en Psicología). Universidad del Rosario, Bogotá, Colombia.

Robbins, S. P. (2018). Management. Harlow: Pearson Educación. Recuperado de http://www.ebooks7-24.com/?il=7485

Rodríguez, E., García, J., Cortes, C. y Puga, J. (junio de 2019). Comparación de las Teorías del Aprendizaje: Una mirada desde el desarrollo curricular y del diseño instruccional en el sistema educativo. Revista Digital de Divulgación e Investigación Turística, 7(7), 4-16. Recuperado de http://tecnocientifica.com.mx/educateconciencia/index.php/KIKAME/article/vie $w / 835 / 731$

Seclén, J. P. (2016). Gestión de la innovación empresarial: un enfoque multinivel. Revista de ciencias de la gestión(1), 16-36. Recuperado de http://revistas.pucp.edu.pe/index.php/360gestion/article/view/14869

Souto, J. E. (2015). Gestión de una cultura de innovación basada en las personas. Journal of Technology Management \& Innovation, 60-65.

Subiela, J. A., Abellón, J., Celdrán, A., Manzanares, J., \& Satorres, B. (2014). La importancia de la Escucha Activa en la intervención Enfermera. Enfermería Global, 13(2), 276-292. Recuperado de http://www.redalyc.org/articulo.oa?id=365834853013

Tapia, J. (2018). Factores críticos que determinan el éxito y la persistencia de la innovación tecnológica de productos y procesos en el sector público peruano: estudio de caso. (Tesis de maestría). Recuperado de http://tesis.pucp.edu.pe/repositorio/

Velapatiño, V. y Perea, H. (5 de julio de 2018). Perú: Innovación una agenda pendiente. Innovación como impulso a la productividad. Recuperado de BBVA Research: https://www.bbvaresearch.com/wp-content/uploads/2018/07/Peru_InnovacionAgendaPendiente.pdf

Vilá, J. (2011). Cultura Innovadora: valores, principios y prácticas de primeros ejecutivos en empresas altamente innovadoras. Recuperado de Open Mind BBVA: https://www.bbvaopenmind.com/articulos/cultura-innovadora-valoresprincipios-y-practicas-de-primeros-ejecutivos-en-empresas-altamenteinnovadoras/

Williams, W. B. y Atinc, G. (2017). "Servant leadership and followership creativity: The influence of workplace spirituality and political skill". Leadership \& Organization Development Journal, 38(2), 178-193. Recuperado de https://doi.org/10.1108/LODJ-02-2015-0019

Ying, S. (16 de marzo de 2016). Does Servant Leadership Inspire Personnel's Innovation Performance: Performance Control as a Moderator. International Journal of Business Administration(2), 86-91. Recuperado de https://pdfs.semanticscholar.org/3625/731f35fd85acf05a5740b2636717cee8fd1 1.pdf 


\section{APÉNDICES}




\section{APÉNDICE 1 FICHA TÉCNICA DE INSTRUMENTO DE EVALUACIÓN}

\begin{tabular}{|c|c|}
\hline Nombre del test: & Diagnóstico Innovación C3 \\
\hline Nombre original: & Diagnóstico de Innovación C3 \\
\hline Autor(es): & Jose Manuel Morales \\
\hline Procedencia: & Chile \\
\hline Adaptación: & Países de Latinoamérica como Chile, Perú, Colombia. \\
\hline Modo de aplicación: & Individual \\
\hline Ámbito de aplicación: & Empresas \\
\hline Edades de aplicación: & Adultos Jóvenes y Adultos \\
\hline Duración: & Entre 15 y 20 minutos \\
\hline $\begin{array}{c}\text { Finalidad: } \\
\text { ¿Qué mide el test? }\end{array}$ & $\begin{array}{l}\text { El Diagnóstico de Innovación C3 mide las capacidades y resulta- } \\
\text { dos de innovación en empresas e instituciones públicas por me- } \\
\text { dio de } 10 \text { dimensiones: apertura externa, apertura interna, auto- } \\
\text { nomía, confianza y colaboración, compromiso estratégico, diver- } \\
\text { sidad, liderazgo, recursos e incentivos, tiempo y trabajo desa- } \\
\text { fiante. }\end{array}$ \\
\hline $\begin{array}{c}\text { Composición/estructura: } \\
\text { (Máximo } 50 \text { palabras) }\end{array}$ & $\begin{array}{c}\text { El Diagnóstico de Innovación C3 está compuesto por } 10 \text { dimen- } \\
\text { siones. } \\
\text { Las dimensiones se construyen a través de } 69 \text { preguntas escala } \\
\text { Likert de } 4 \text { categorías de respuestas. }\end{array}$ \\
\hline Baremación: & $\begin{array}{l}11 \text { empresas chilenas, con mas de } 100 \text { empleados cada una, las } \\
\text { cuales participaron en el Ranking de Cultura de Creativa Corpo- } \\
\text { rativa de los sectores de: Automóvil, Construcción, Energía, Bie- } \\
\text { nes y Raices, Fabricación, Minería, Finanzas, Tecnología e } \\
\text { Industrias de transporte. La encuesta fue completada por } 1.983 \\
\text { empleados bajo contrato, a partir de enero } \\
\text { a septiembre de 2014. La tasa de respuesta promedio entre las } \\
\text { empresas fue del } 51 \%\end{array}$ \\
\hline Editores: & Jose Manuel Morales \\
\hline Datos de publicación: & 2015 agosto - Chile \\
\hline
\end{tabular}




\section{APÉNDICE 2 DISEÑO INSTRUCCIONAL TALLER 1 - CAMBIO DE MINDSET E INTRODUC- CIÓN AL DESIGN THINKING}

\begin{tabular}{|c|c|c|c|c|c|c|}
\hline \multicolumn{7}{|c|}{$\begin{array}{c}\text { Resultado de Aprendizaje: Los líderes entienden la importancia del trabajo colaborativo y de la capacidad de escucha en su rol, y conocen la aplicación de una nueva } \\
\text { metodología de trabajo. }\end{array}$} \\
\hline \multicolumn{7}{|c|}{$\begin{array}{l}\text { Módulo o Taller 1: Cambio de Mindset e Introducción al Design Thinking } \\
\text { Sesión 1: } 8 \text { horas }\end{array}$} \\
\hline Etapa & Tarea/Fase & $\begin{array}{l}\text { Objetivo de Apren- } \\
\text { dizaje }\end{array}$ & Actividades & Recursos / Materiales & Tiempo & $\begin{array}{l}\text { Instrumento } \\
\text { de Evaluación }\end{array}$ \\
\hline \multirow{3}{*}{ Inicio } & Llegada & - & $\begin{array}{l}\text { Recepción de participantes colocándoles sus nombres con su } \\
\text { mesa asignada y solicitarles puedan ubicarse en sus mesas. }\end{array}$ & $\begin{array}{l}\text { Música ambiental } \\
\text { Adhesivos con los nom- } \\
\text { bres y números de mesa }\end{array}$ & $15 \min$ & - \\
\hline & $\begin{array}{l}\text { Bienvenida y } \\
\text { Rapport }\end{array}$ & $\begin{array}{l}\text { Conocer al docente } \\
\text { Tomar conciencia de } \\
\text { la necesidad de cam- } \\
\text { bio. }\end{array}$ & $\begin{array}{l}\text { Presentación del docente. } \\
\text { Bienvenida y agradecimiento por dedicación del tiempo al ta- } \\
\text { ller. } \\
\text { Se comenta el objetivo de aprendizaje del taller. } \\
\text { Se muestra un video sobre la importancia de cambiar (des- } \\
\text { aprender para aprender) } \\
\text { Se realiza una reflexión del video sobre la importancia de } \\
\text { cambiar y la necesidad de desaprender para aprender. }\end{array}$ & $\begin{array}{l}\text { PPT } \\
\text { Video } \\
\text { https://www.youtube.co } \\
\text { m/watch?v=7- } \\
\text { vgu2Ej2E0\&t=35s }\end{array}$ & $25 \min$ & \\
\hline & $\begin{array}{l}\text { Generación de } \\
\text { confianza y em- } \\
\text { patía } \\
\text { Reconocimiento } \\
\text { del público }\end{array}$ & $\begin{array}{l}\text { Reconocer compor- } \\
\text { tamientos de la cul- } \\
\text { tura y de sus posturas } \\
\text { como líderes. }\end{array}$ & $\begin{array}{l}\text { Docente muestra una pregunta en una PPT: } \\
\text { ¿Qué expectativas tenemos del Taller? } \\
\text { ¿Cómo es nuestra cultura y cómo somos los líderes? } \\
\text { Se realiza una discusión grupal de las preguntas en sus mesas } \\
\text { de trabajo. } \\
\text { Un representante de cada grupo comparte las respuestas. } \\
\text { Docente apunta en papelote expectativas y características de } \\
\text { la cultura y del líder compartidas por cada grupo. }\end{array}$ & $\begin{array}{l}\text { PPT } \\
\text { Papelote } \\
\text { Plumones de colores }\end{array}$ & $20 \mathrm{~min}$ & - \\
\hline
\end{tabular}




\begin{tabular}{|c|c|c|c|c|c|c|}
\hline \multirow{4}{*}{$\begin{array}{l}\text { Procesa- } \\
\text { miento de } \\
\text { Informa- } \\
\text { ción y } \\
\text { Desarro- } \\
\text { llo }\end{array}$} & $\begin{array}{l}\text { Concepto e im- } \\
\text { portancia del Li- } \\
\text { derazgo }\end{array}$ & $\begin{array}{l}\text { Conocer la importan- } \\
\text { cia del rol del líder } \\
\text { en la organización. } \\
\text { Conocer las compe- } \\
\text { tencias asociadas al } \\
\text { liderazgo que se } \\
\text { busca promover }\end{array}$ & $\begin{array}{l}\text { Presentación del docente en una PPT acerca de: } \\
\text { - la importancia del rol del líder para una cultura organizacio- } \\
\text { nal } \\
\text { - la importancia del desarrollo de la capacidad de confianza, } \\
\text { trabajo colaborativo, escucha activa y empatía en un equipo. } \\
\text { El docente propone ejemplos acerca de los tipos de liderazgo, } \\
\text { el impacto en la consecución de resultados y en la motivación } \\
\text { del equipo. }\end{array}$ & PPT & $45 \mathrm{~min}$ & - \\
\hline & \multicolumn{4}{|c|}{$B R E A K$} & $15 \min$ & \\
\hline & $\begin{array}{l}\text { Dinámica del lí- } \\
\text { der y escucha ac- } \\
\text { tiva }\end{array}$ & $\begin{array}{l}\text { Tomar conciencia } \\
\text { acerca del comporta- } \\
\text { miento de no antici- } \\
\text { parse y de no inter- } \\
\text { pretar. }\end{array}$ & $\begin{array}{l}\text { Docente dirige una dinámica: "De los pulgares" de la si- } \\
\text { guiente manera: } \\
\text { a. Realiza pregunta: ¿Conocen el juego de los pulgares? } \\
\text { b. Brinda instrucción: "Ahora júntense en parejas y realicen } \\
\text { la mayor cantidad de veces de presiones del pulgar de su pa- } \\
\text { reja que les sea posible durante } 1 \text { minuto”. } \\
\text { c. Los participantes realizan la actividad. } \\
\text { d. Docente dirige reflexión acerca de la importancia de escu- } \\
\text { char y no anticiparse o interpretar. }\end{array}$ & - & $15 \mathrm{~min}$ & - \\
\hline & $\begin{array}{l}\text { Introducción de } \\
\text { Nueva Metodo- } \\
\text { logía de Trabajo } \\
\text { e importancia del } \\
\text { rol del líder }\end{array}$ & $\begin{array}{l}\text { Conocer el concepto } \\
\text { de agente de cambio, } \\
\text { nuevas metodologías } \\
\text { de trabajo y el im- } \\
\text { pacto en la organiza- } \\
\text { ción. }\end{array}$ & $\begin{array}{l}\text { Docente introduce la importancia del rol del líder como } \\
\text { agente de cambio para la introducción de nuevas metodolo- } \\
\text { gías de trabajo por medio de una presentación con conceptos } \\
\text { claves: } \\
\text { ¿Qué es un agente de cambio? } \\
\text { ¿Por qué es necesario conocer y aplicar nuevas metodologías } \\
\text { de trabajo? } \\
\text { ¿Cuál es el impacto de un agente de cambio en la inserción } \\
\text { de nuevas metodologías de trabajo en una organización? }\end{array}$ & PPT & $15 \min$ & \\
\hline
\end{tabular}




\begin{tabular}{|c|c|c|c|c|c|c|}
\hline & $\begin{array}{l}\text { Reconocimiento } \\
\text { de la Metodolo- } \\
\text { gía }\end{array}$ & $\begin{array}{l}\text { Conocer el concepto } \\
\text { de Design Thinking } \\
\text { y las etapas de la me- } \\
\text { todología, identifi- } \\
\text { cando los comporta- } \\
\text { mientos más impor- } \\
\text { tantes asociados a } \\
\text { cada una de ellas. }\end{array}$ & $\begin{array}{l}\text { Docente presenta Introducción a la Metodología de Design } \\
\text { Thinking considerando comportamientos asociados a cada } \\
\text { una de las etapas y apoyándose en } 2 \text { videos. } \\
\text { Conceptos a desarrollar: } \\
\text { - Identificación del problema (cuestionar) } \\
\text { - Empatía (no anticiparse, aceptar diferentes opiniones, no } \\
\text { juzgar, no interpretar) } \\
\text { - Ideación (crear) } \\
\text { - Prototipado y testing (arriesgarse, ser resiliente) } \\
\text { - Storytelling }\end{array}$ & $\begin{array}{l}\text { PPT } \\
\text { Video: } \\
\text { https://www.youtube.co } \\
\text { m/watch?v=gIjlxmPJ4v } \\
\text { Y } \\
\text { https://www.youtube.co } \\
\text { m/watch?v=hRE6P_FY } \\
\text { 2rE }\end{array}$ & $120 \mathrm{~min}$ & - - \\
\hline & \multicolumn{4}{|c|}{ BREAK - ALMUERZO } & $90 \mathrm{~min}$ & \\
\hline \multirow{2}{*}{$\begin{array}{l}\text { Refuerzo } \\
\text { de } \\
\text { Aprendi- } \\
\text { zajes }\end{array}$} & \multirow[t]{2}{*}{$\begin{array}{l}\text { Desarrollo de la } \\
\text { Metodología }\end{array}$} & $\begin{array}{l}\text { Identificar un pro- } \\
\text { blema en equipo me- } \\
\text { diante el cuestiona- } \\
\text { miento y poniendo } \\
\text { en práctica la escu- } \\
\text { cha activa mediante } \\
\text { la no interpretación } \\
\text { ni anticipación y la } \\
\text { aceptación de dife- } \\
\text { rentes opiniones. }\end{array}$ & $\begin{array}{l}\text { Docente dirige la siguiente actividad: } \\
\text { Docente brinda indicación para que se identifiquen problemas } \\
\text { u oportunidades de mejora específicos de la empresa en cada } \\
\text { equipo considerando la metodología revisada anteriormente y } \\
\text { la importancia de la escucha activa. }\end{array}$ & $\begin{array}{l}\text { Papelote } \\
\text { Plumones }\end{array}$ & $45 \min$ & $\begin{array}{l}\text { Registro de ob- } \\
\text { servación de } \\
\text { comportamien- } \\
\text { tos asociados a } \\
\text { la escucha ac- } \\
\text { tiva durante la } \\
\text { conversación } \\
\text { grupal para el } \\
\text { logro de la } \\
\text { identificación } \\
\text { del problema. }\end{array}$ \\
\hline & & $\begin{array}{l}\text { Realizar el mapa de } \\
\text { empatía por medio } \\
\text { de la recolección de } \\
\text { información ejer- } \\
\text { ciendo la escucha ac- } \\
\text { tiva considerando los } \\
\text { comportamientos } \\
\text { asociados. }\end{array}$ & $\begin{array}{l}\text { Docente dirige la siguiente actividad: } \\
\text { Se desarrolla una simulación del proceso de empatía me- } \\
\text { diante entrevistas entre los grupos de trabajo e intercambio de } \\
\text { opiniones en donde la escucha activa toma un papel impor- } \\
\text { tante para el desarrollo de la Matriz de Empatía (se sigue in- } \\
\text { centivando la no anticipación, no interpretación de respues- } \\
\text { tas, aceptaación de opiniones diferentes y el no juzgar o emi- } \\
\text { tir juicios). }\end{array}$ & $\begin{array}{l}\text { Papelote } \\
\text { Hojas Bond } \\
\text { Lápices } \\
\text { Post It } \\
\text { PPT con Matriz de em- } \\
\text { patía }\end{array}$ & $30 \min$ & $\begin{array}{l}\text { Realización de } \\
\text { la Matriz de } \\
\text { Empatía }\end{array}$ \\
\hline
\end{tabular}




\begin{tabular}{|c|c|c|c|c|c|c|}
\hline & & $\begin{array}{l}\text { Realizar una priori- } \\
\text { zación de soluciones } \\
\text { propuestas de ma- } \\
\text { nera grupal ejer- } \\
\text { ciendo la escucha ac- } \\
\text { tiva e introduciendo } \\
\text { el trabajo colabora- } \\
\text { tivo mediante el lo- } \\
\text { gro de consensos. }\end{array}$ & $\begin{array}{l}\text { Docente dirige la siguiente actividad: } \\
\text { Desarrollo del proceso de ideación en } 2 \text { fases: } \\
\text { 1. Divergencia: mediante técnica de brainstorming. (todos los } \\
\text { integrantes del grupo tienen un tiempo determinado para co- } \\
\text { locar en el papelote todas las ideas que tengan en mente) } \\
\text { 2. Convergencia: se agrupan ideas del paso anterior en tipo de } \\
\text { soluciones y priorizándolas. (se incentiva la escucha activa ya } \\
\text { que se resalta la importancia de aceptar opiniones diferentes, } \\
\text { no emitir juicios y se introduce la necesidad de trabajar de } \\
\text { manera colaborativa llegando a consensos, apoyándose entre } \\
\text { todos para el logro del objetivo). }\end{array}$ & $\begin{array}{l}\text { Papelote } \\
\text { Post it } \\
\text { Lapiceros } \\
\text { Lápices } \\
\text { Plumones }\end{array}$ & $30 \mathrm{~min}$ & $\begin{array}{l}\text { Realización de } \\
\text { la priorización } \\
\text { de soluciones } \\
\text { en un papelote. }\end{array}$ \\
\hline & & $\begin{array}{l}\text { Realizar un prototipo } \\
\text { de solución por me- } \\
\text { dio del trabajo cola- } \\
\text { borativo. }\end{array}$ & $\begin{array}{l}\text { Docente dirige la siguiente actividad: } \\
\text { Desarrollo del proceso de prototipado } \\
\text { En esta fase se desarrolla el esquema de la solución escogida } \\
\text { en el punto anterior y mediante el feedback de los otros gru- } \\
\text { pos se va mejorando. (se ejerce la escucha activa y trabajo } \\
\text { colaborativo) } \\
\text { Luego se toma este esquema para elaborar el prototipo (con } \\
\text { diversos materiales) y recibir nuevamente feedback poniendo } \\
\text { en práctica técnicas para el desarrollo de un trabajo colabora- } \\
\text { tivo efectivo. (intercambio de opiniones, apoyo en el logro } \\
\text { del objetivo, logro de consensos, feedbacks constantes). }\end{array}$ & $\begin{array}{l}\text { Plastilinas, colores, } \\
\text { goma, hojas bond, plu- } \\
\text { mones, post it. }\end{array}$ & $90 \min$ & $\begin{array}{l}\text { Realización del } \\
\text { prototipo consi- } \\
\text { derando el } \\
\text { feedback del } \\
\text { otro equipo. }\end{array}$ \\
\hline $\begin{array}{l}\text { Cierre de } \\
\text { la sesión }\end{array}$ & $\begin{array}{l}\text { Resumen y cie- } \\
\text { rre de sesión }\end{array}$ & $\begin{array}{l}\text { Identificar los princi- } \\
\text { pales conceptos tra- } \\
\text { bajados y los com- } \\
\text { portamientos asocia- } \\
\text { dos. }\end{array}$ & $\begin{array}{l}\text { Docente realiza un resumen de los principales conceptos tra- } \\
\text { bajados en la sesión: } \\
\text { Líderes como agentes de cambio } \\
\text { Nuevas metodologías de trabajo } \\
\text { Design Thinking } \\
\text { Escucha activa (no anticiparse a la acción, no interpretar, } \\
\text { aceptar opiniones diferentes, no juzgar y no emitir juicios). } \\
\text { Trabajo colaborativo (intercambio de opiniones, apoyo en el } \\
\text { logro de objetivos, logro de consensos, feedbacks constan- } \\
\text { tes). }\end{array}$ & PPT & $10 \min$ & - \\
\hline
\end{tabular}




\begin{tabular}{|c|c|c|c|c|c|c|}
\hline \multicolumn{7}{|c|}{$\begin{array}{l}\text { Resultado de Aprendizaje: Los líderes entienden la importancia del trabajo colaborativo y de la capacidad de escucha en su rol, y conocen la aplicación de una nueva } \\
\text { metodología de trabajo. }\end{array}$} \\
\hline \multicolumn{7}{|c|}{$\begin{array}{l}\text { Módulo o Taller 1: Cambio de Mindset e Introducción al Design Thinking } \\
\text { Sesión 2: } 4 \text { horas }\end{array}$} \\
\hline Etapa & Tarea/Fase & Objetivo de Aprendizaje & Actividades & Recursos / Materiales & Tiempo & $\begin{array}{c}\text { Instru- } \\
\text { mento de } \\
\text { Evaluación }\end{array}$ \\
\hline Inicio & Bienvenida & - & $\begin{array}{l}\text { Recepción de participantes y ubica- } \\
\text { ción en sus sitios }\end{array}$ & & $15 \min$ & - \\
\hline \multirow{2}{*}{$\begin{array}{l}\text { Refuerzo } \\
\text { de } \\
\text { Aprendi- } \\
\text { zajes }\end{array}$} & $\begin{array}{l}\text { Transmisión de } \\
\text { técnicas de pre- } \\
\text { sentación }\end{array}$ & $\begin{array}{l}\text { Conocer técnicas de pre- } \\
\text { sentación de un prototipo. }\end{array}$ & $\begin{array}{l}\text { Docente comparte técnicas para } \\
\text { elaborar una presentación del proto- } \\
\text { tipo elaborado en los pasos anterio- } \\
\text { res. (Storytelling) }\end{array}$ & PPT & $30 \min$ & - \\
\hline & $\begin{array}{l}\text { Exposición gru- } \\
\text { pal }\end{array}$ & $\begin{array}{l}\text { Aplicar técnicas de pre- } \\
\text { sentación y recepcionar } \\
\text { los feedbacks adecuada- } \\
\text { mente. }\end{array}$ & $\begin{array}{l}\text { Cada grupo expone su propuesta de } \\
\text { solución a los demás grupos consi- } \\
\text { derando un tiempo definido para la } \\
\text { exposición de } 10 \text { min y } 5 \text { min de } \\
\text { preguntas y feedbacks. }\end{array}$ & $\begin{array}{l}\text { Papelote } \\
\text { Prototipo } \\
\text { Pizarra / plumones }\end{array}$ & $90 \mathrm{~min}$ & $\begin{array}{l}\text { Observa- } \\
\text { ción de las } \\
\text { conductas } \\
\text { de presenta- } \\
\text { ción }\end{array}$ \\
\hline \multirow[t]{2}{*}{$\begin{array}{l}\text { Sistema- } \\
\text { tización y } \\
\text { Cierre }\end{array}$} & Cierre & $\begin{array}{l}\text { Reconocer aquellas habili- } \\
\text { dades de un líder necesa- } \\
\text { rias para la innovación y } \\
\text { repensar en la necesidad } \\
\text { de trabajo colaborativo y } \\
\text { escucha activa. }\end{array}$ & $\begin{array}{l}\text { Actividad de cierre: presentación fi- } \\
\text { nal de video acerca de un ejemplo } \\
\text { de un líder innovador } \\
\text { Reflexión abierta: ¿Cómo los parti- } \\
\text { cipantes asocian los conceptos y las } \\
\text { habilidades aprendidas durante las } \\
\text { dos sesiones con lo que demuestra } \\
\text { Steve Jobs en su corta exposición? }\end{array}$ & https://www.youtube.com/watch?v=YQRtwnP2ub0 & $30 \mathrm{~min}$ & \\
\hline & & & $\begin{array}{l}\text { Evaluación final - Encuesta } \\
\text { Palabras de cierre }\end{array}$ & & $15 \mathrm{~min}$ & $\begin{array}{l}\text { Encuesta } \\
\text { Final }\end{array}$ \\
\hline
\end{tabular}




\section{APÉNDICE 3 MAPA DE EMPATÍA}

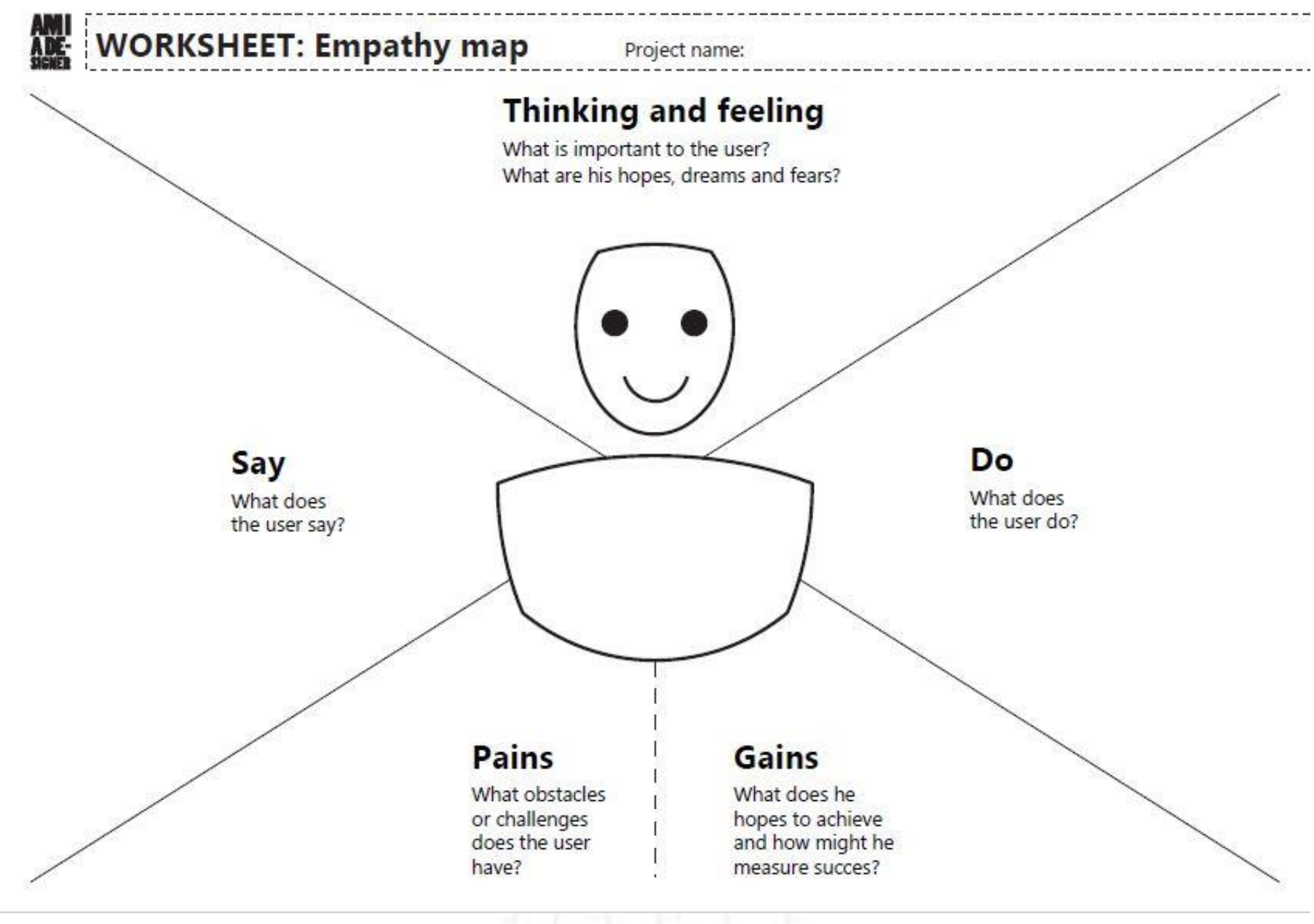




\section{APÉNDICE 4 ENCUESTA FINAL TALLER 1}

\section{Taller: Cambio de Mindset e Introducción al Design Thinking Encuesta Final}

Con el fin de conocer tu opinión acerca del presente taller y continuar mejorando nuestros planes de formación, te pedimos contestar a las siguientes tres preguntas. Todas las preguntas son para marcar.

1. ¿Consideras que el taller ha sido útil para tu rol de líder en la compañía?

Totalmente en Desacuerdo

En Desacuerdo

Ni de acuerdo ni en desacuerdo

De acuerdo

Totalmente De acuerdo

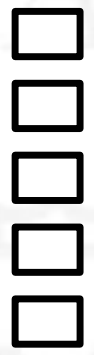

2. Considerando un puntaje del 1 al 5 en donde 1 es poco y 5 es mucho, ¿Qué tan importante consideras la Innovación para la compañía?

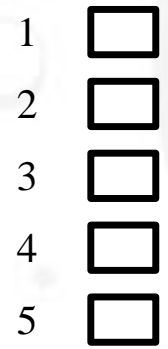

3. Luego de trabajar las habilidades de Capacidad de escucha, Trabajo Colaborativo y Empatía, ¿consideras que son habilidades esenciales en tu rol de líder para la consecución de objetivos de innovación?

Totalmente en Desacuerdo

En Desacuerdo

Ni de acuerdo ni en desacuerdo

De acuerdo

Totalmente De acuerdo

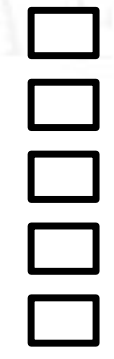




\section{APÉNDICE 5 DISEÑO INSTRUCCIONAL TALLER 2 - METODOLOGÍAS ÁGILES E INTRO- DUCCIÓN A SCRUM}

\begin{tabular}{|c|c|c|c|c|c|c|}
\hline \multicolumn{7}{|c|}{ Resultado de Aprendizaje: Los líderes conocen y ejecutan diferentes prácticas laborales asociadas a la capacidad de escucha y trabajo colaborativo. } \\
\hline \multicolumn{7}{|c|}{$\begin{array}{l}\text { Módulo o Taller 2: Metodologías ágiles e Introducción a SCRUM } \\
\text { Sesión 1: } 4 \text { horas }\end{array}$} \\
\hline Etapa & Tarea/Fase & $\begin{array}{l}\text { Objetivo de Aprendi- } \\
\text { zaje }\end{array}$ & Actividades & Recursos / Materiales & Tiempo & $\begin{array}{l}\text { Instrumento de } \\
\text { Evaluación }\end{array}$ \\
\hline \multirow{3}{*}{ Inicio } & Llegada & - & $\begin{array}{l}\text { Recepción de participantes y ubicación en sus mesas de tra- } \\
\text { bajo } \\
\text { (grupos previamente armados y números de mesas asignadas) }\end{array}$ & Cartel de número de mesas & $15 \mathrm{~min}$ & \\
\hline & $\begin{array}{l}\text { Bienvenida } \\
\text { y Rapport }\end{array}$ & - & $\begin{array}{l}\text { Docente recuerda su nombre, recuerda el objetivo del taller } \\
\text { anterior y comenta el nuevo objetivo de aprendizaje del pre- } \\
\text { sente taller. }\end{array}$ & PPT & $10 \mathrm{~min}$ & - \\
\hline & $\begin{array}{l}\text { Introduc- } \\
\text { ción a con- } \\
\text { ceptos im- } \\
\text { portantes }\end{array}$ & $\begin{array}{l}\text { Conocer la importancia } \\
\text { de adaptarse frente a los } \\
\text { cambios y la importan- } \\
\text { cia del uso de metodolo- } \\
\text { gías ágiles. }\end{array}$ & $\begin{array}{l}\text { Docente recuerda la importancia del cambio y se plantea la } \\
\text { necesidad de adaptarse a los cambios de manera "ágil", con lo } \\
\text { cual se justifica el uso de metodologías ágiles. }\end{array}$ & PPT & $10 \mathrm{~min}$ & \\
\hline $\begin{array}{l}\text { Procesa- } \\
\text { miento de } \\
\text { Informa- } \\
\text { ción y } \\
\text { Desarrollo }\end{array}$ & $\begin{array}{l}\text { Presenta- } \\
\text { ción de la } \\
\text { Metodolo- } \\
\text { gía } \\
\text { SCRUM }\end{array}$ & $\begin{array}{l}\text { Conocer las ventajas y } \\
\text { ámbitos ed aplicación de } \\
\text { la metodología SCRUM }\end{array}$ & $\begin{array}{l}\text { Docente presenta la Metodología ágil SCRUM, las ventajas y } \\
\text { los ámbitos de aplicación de la misma. }\end{array}$ & PPT & $25 \mathrm{~min}$ & \\
\hline
\end{tabular}




\begin{tabular}{|c|c|c|c|c|c|}
\hline Dinámica 1 & $\begin{array}{l}\text { Reconocer la necesidad } \\
\text { de trabajar en equipo } \\
\text { para obtener resultados } \\
\text { ágiles y tener un acerca- } \\
\text { miento a la dinámica } \\
\text { SCRUM }\end{array}$ & $\begin{array}{l}\text { Docente dirige dinámica de "Importancia del trabajo en } \\
\text { grupo" }\end{array}$ & $\begin{array}{l}\text { Hojas bond, lapiceros, lápi- } \\
\text { ces, } 10 \text { monedas }\end{array}$ & $15 \mathrm{~min}$ & - \\
\hline \multirow{3}{*}{$\begin{array}{l}\text { Reflexiones } \\
\text { e Introduc- } \\
\text { ción a la } \\
\text { Metodolo- } \\
\text { gía } \\
\text { SCRUM }\end{array}$} & $\begin{array}{l}\text { Ser concientes del cam- } \\
\text { bio de paradigma y en } \\
\text { las formas de trabajar } \\
\text { que se requiere hacer } \\
\text { para aplicar metodolo- } \\
\text { gías ágiles. }\end{array}$ & $\begin{array}{l}\text { Docente presenta un video: Joe Justice - Wikispeed y se re- } \\
\text { flexiona sobre la exigencia de un cambio de paradigma para } \\
\text { trabajar con metodologías ágiles. }\end{array}$ & $\begin{array}{l}\text { Video: } \\
\text { https://www.youtube.com/ } \\
\text { watch?v=Zxw19EFs8WM } \\
\text { \&feature=youtu.be }\end{array}$ & $10 \mathrm{~min}$ & - \\
\hline & $\begin{array}{l}\text { Entender la nueva defi- } \\
\text { nición de éxtio en la } \\
\text { consecusión de un pro- } \\
\text { yecto. }\end{array}$ & $\begin{array}{l}\text { Docente plantea una RE-DEFINICIÓN DEL ÉXITO como: } \\
\text { cambiar el enfoque centrado en el proyecto (alcanzar lo acor- } \\
\text { dado), hacia uno centrado en el producto (generar valor) }\end{array}$ & PPT & $10 \mathrm{~min}$ & - \\
\hline & $\begin{array}{l}\text { Conocer las pautas bási- } \\
\text { cas para trabajar bajo la } \\
\text { metodología SCRUM }\end{array}$ & $\begin{array}{l}\text { Docente propone las pautas básicas para trabajar SCRUM: } \\
\text { - Trabajar en equipo } \\
\text { - Comunicar los avances al grupo } \\
\text { - El líder como promotor de espacios de trabajo y orientado al } \\
\text { aprendizaje continuo }\end{array}$ & PPT & $10 \mathrm{~min}$ & - \\
\hline \multicolumn{4}{|c|}{$B R E A K$} & $15 \mathrm{~min}$ & \\
\hline
\end{tabular}




\begin{tabular}{|c|c|c|c|c|c|c|}
\hline \multirow{3}{*}{$\begin{array}{l}\text { Refuerzo } \\
\text { de Apren- } \\
\text { dizajes }\end{array}$} & Dinámica 2 & $\begin{array}{l}\text { Reconocer las formas en } \\
\text { las que se relacionan } \\
\text { con sus equipos de tra- } \\
\text { bajo }\end{array}$ & $\begin{array}{l}\text { Docente dirige dinámica } 2 \text { de: " Evaluar estilo de trabajo en } \\
\text { equipo". } \\
\text { A. Se plantea que de manera individual las personas evalúen } \\
\text { cómo se dan la toma de decisiones según el área en la que tra- } \\
\text { bajan. } \\
\text { B. Luego los participantes deben escribir sus reflexiones indi- } \\
\text { viduales en el papelote siguiendo el esquema planteado (área } \\
\text { de autoridad, área de delegación), respondiendo a las pregun- } \\
\text { tas siguientes: } \\
\text { - ¿cuáles son las características de la autoridad y de los equi- } \\
\text { pos delegados? } \\
\text { - ¿En qué parte del eje nos encontramos? } \\
\text { - ¿Qué hacemos para pasar de A a B? }\end{array}$ & $\begin{array}{l}\text { Hojas bond, lapiceros, } \\
\text { lápices, } \\
\text { Post it } \\
\text { PPT }\end{array}$ & $30 \mathrm{~min}$ & $\begin{array}{l}\text { Matriz de identifi- } \\
\text { cación de caracte- } \\
\text { rísticas de estilo } \\
\text { de trabajo. }\end{array}$ \\
\hline & $\begin{array}{l}\text { Conoci- } \\
\text { miento de la } \\
\text { metodolo- } \\
\text { gía } \\
\text { SCRUM }\end{array}$ & $\begin{array}{l}\text { Conocer los elementos } \\
\text { básicos de la metodlogía } \\
\text { SCRUM y reflexionar } \\
\text { acerca de las necesida- } \\
\text { des para articular las ini- } \\
\text { ciativas de las áreas de } \\
\text { la compañía. }\end{array}$ & $\begin{array}{l}\text { Docente explica los elementos básicos para el desarrollo de la } \\
\text { metodología SCRUM: } \\
\text { - Principios } \\
\text { - Roles } \\
\text { - Artefactos } \\
\text { - Actividades } \\
\text { Al finalizar la presentación expone la siguiente pregunta: } \\
\text { ¿Cómo articulr las iniciativas entre áreas para el logro de ob- } \\
\text { jetivos estratégicos comunes? }\end{array}$ & PPT & $20 \mathrm{~min}$ & - \\
\hline & Dinámica 3 & $\begin{array}{l}\text { Plantear ideas relaciona- } \\
\text { das al contexto laboral } \\
\text { para la aplicación de la } \\
\text { metodología SCRUM }\end{array}$ & $\begin{array}{l}\text { Docente dirige la dinámica brindando las siguientes indica- } \\
\text { ciones: } \\
\text { A. De manera individual plantear un proyecto que articule las } \\
\text { áreas y se focalice en los objetivos estratégicos de la compa- } \\
\text { ñía. } \\
\text { B. Socializar sus proyectos con su grupo y seleccionar uno } \\
\text { sólo por grupo. }\end{array}$ & $\begin{array}{l}\text { Hojas bond, lápices, lapice- } \\
\text { ros }\end{array}$ & $20 \mathrm{~min}$ & - \\
\hline
\end{tabular}




\begin{tabular}{|c|c|c|c|c|c|c|}
\hline & $\begin{array}{l}\text { Aplicación } \\
\text { de la meto- } \\
\text { dología }\end{array}$ & $\begin{array}{l}\text { Recolectar de manera } \\
\text { grupal los datos implica- } \\
\text { dos en la ejecución del } \\
\text { proyecto por medio de } \\
\text { los comportamientos } \\
\text { asociados a la escucha } \\
\text { activa y al trabajo cola- } \\
\text { borativo. }\end{array}$ & $\begin{array}{l}\text { Docente comparte técnica de recolección de datos para la eje- } \\
\text { cución de los proyectos, mediante la técnicas de "generación } \\
\text { de historias de usuarios" basándose en las 3C's. (Card, Con- } \\
\text { versation y Confirmation). } \\
\text { Luego dirige dinámica para la aplicación de la técnica en los } \\
\text { equipos asgurando que esta técnica de historia de usuarios se } \\
\text { guiada por comportamientos de la esucha activa, de la con- } \\
\text { versación e intercambio de opiniones en grupo, así como el } \\
\text { consenso y acuerdos para la toma de decisiones en un trabajo } \\
\text { colaborativo. }\end{array}$ & $\begin{array}{l}\text { Hojas bond, papelote, plu- } \\
\text { mones, lapices }\end{array}$ & $20 \min$ & - \\
\hline & $\begin{array}{l}\text { Aplicación } \\
\text { de la meto- } \\
\text { dología }\end{array}$ & $\begin{array}{l}\text { Realizar un Product Ba- } \\
\text { kclog por equipo consi- } \\
\text { derando el consenso en- } \\
\text { tre los miembros para la } \\
\text { priorización de tareas. }\end{array}$ & $\begin{array}{l}\text { Docente indica cómo definir las historias de los usuarios en } \\
\text { un "Product Backlog" y cómo organizarlo. } \\
\text { Participantes desarrollan su Product Backlog por equipos. }\end{array}$ & Papelote & 30 min & $\begin{array}{l}\text { Registro de obser- } \\
\text { vación de los } \\
\text { comportamientos } \\
\text { básicos asociados } \\
\text { a la escucha ac- } \\
\text { tiva y trabajo co- } \\
\text { laborativo durante } \\
\text { la realización del } \\
\text { Product Backlog. }\end{array}$ \\
\hline $\begin{array}{l}\text { Cierre de } \\
\text { la sesión }\end{array}$ & Cierre & $\begin{array}{l}\text { Identificar los principa- } \\
\text { les conceptos trabajados } \\
\text { y los comportamientos } \\
\text { asociados. }\end{array}$ & $\begin{array}{l}\text { Docente realiza un resumen de los principales conceptos tra- } \\
\text { bajados en la sesión: } \\
\text { Adaptación al cambio } \\
\text { SCRUM } \\
\text { Refuerzo del trabajo colaborativo (intercambio de opiniones, } \\
\text { apoyo en el logro de objetivos, logro de consensos, feedbacks } \\
\text { constantes). }\end{array}$ & PPT & $15 \mathrm{~min}$ & - \\
\hline
\end{tabular}


APÉNDICE 6 MATRIZ DE IDENTIFICACIÓN DE CARACTERÍSTICAS DE ESTILO DE TRABAJO

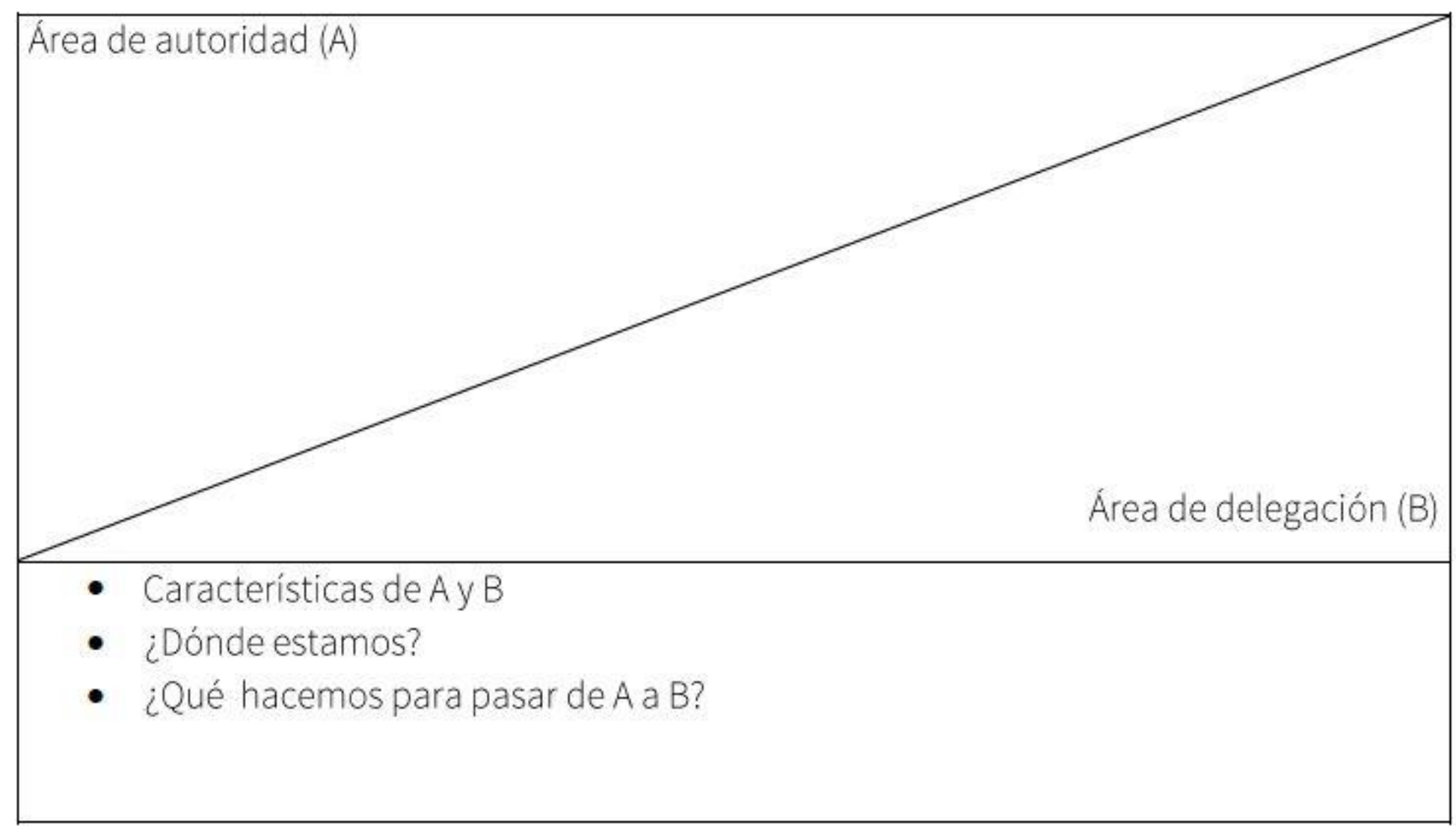




\section{APÉNDICE 7 ENCUESTA FINAL TALLER 2}

\section{Taller: Metodologías ágiles e Introducción a SCRUM \\ Encuesta Final}

Con el fin de conocer tu opinión acerca del presente taller y continuar mejorando nuestros planes de formación, te pedimos contestar a las siguientes tres preguntas. Todas las preguntas son para marcar.

1. ¿Consideras que el taller ha sido útil para tu rol de líder en la compañía?

Totalmente en Desacuerdo

En Desacuerdo

$\mathrm{Ni}$ de acuerdo ni en desacuerdo

De acuerdo

Totalmente De acuerdo

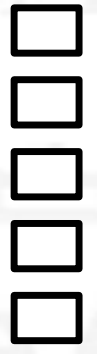

2. ¿Consideras que es posible aplicar las técnicas de trabajo colaborativo o metodologías ágiles como SCRUM en proyectos estratégicos actuales de la compañía?

Totalmente en Desacuerdo

En Desacuerdo

Ni de acuerdo ni en desacuerdo

De acuerdo

Totalmente De acuerdo

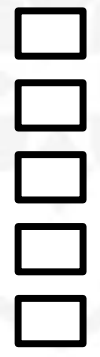

3. ¿Sabes qué cambios realizar en la dinámica de tu equipo para fomentar la aplicación de técnicas de trabajo colaborativo para el logro de resultados y objetivos en el área?

SI

NO

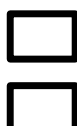




\title{
APÉNDICE 8 PRODUCTOS DE APRENDIZAJE
}

\author{
Descripción de los productos de aprendizaje incorporados por los líderes en la ejecu- \\ ción de proyectos y direccionamiento de sus equipos. \\ prácticas de Daily Meetings.
}

\begin{tabular}{|c|c|c|}
\hline $\begin{array}{c}\text { Producto 1: Sesiones de Trabajo } \\
\text { Colaborativas }\end{array}$ & $\begin{array}{c}\text { Producto 2: Generación de Comité In- } \\
\text { terdisciplinario }\end{array}$ & $\begin{array}{c}\text { Producto 3: Ejecución de Daily } \\
\text { Meetings }\end{array}$ \\
\hline $\begin{array}{l}\text { - } 12 \text { sesiones de trabajo colabo- } \\
\text { rativo (TC) para culminar cada } \\
\text { fase del proyecto "CD" de ma- } \\
\text { nera exitosa. } \\
\text { En total fueron } 4 \text { fases de } 12 \\
\text { sesiones cada una que se desa- } \\
\text { rrollaban en } 3 \text { sesiones sema- } \\
\text { nales, es decir en } 1 \text { mes culmi- } \\
\text { naban } 1 \text { fase. } \\
\text { Logro: } 3 \text { de } 4 \text { fases del pro- } \\
\text { yecto culminadas de manera } \\
\text { exitosa en los tiempos defini- } \\
\text { dos y evidenciando los com- } \\
\text { portamientos asociados al TC. } \\
8 \text { sesiones de trabajo colabora- } \\
\text { tivo para culminar las fases del } \\
\text { proyecto "AT" de manera exi- } \\
\text { tosa. } \\
\text { En total fueron } 3 \text { fases de } 8 \text { se- } \\
\text { siones cada una que se desarro- } \\
\text { llaban en } 1 \text { sesión semanal, es } \\
\text { decir en } 2 \text { meses culminaban } 1 \\
\text { fase. } \\
\text { Logro: } 2 \text { fases del proyecto } \\
\text { culminadas de manera exitosa } \\
\text { en los tiempos definidos y evi- } \\
\text { denciando los comportamien- } \\
\text { tos asociados al TC. }\end{array}$ & $\begin{array}{l}\text { - Generación de Comité Interdiscipli- } \\
\text { nario con periodicidad quincenal } \\
\text { para la toma de decisiones oportunas } \\
\text { sobre los proyectos en curso y logro } \\
\text { de los objetivos en los tiempos pro- } \\
\text { puestos. } \\
\text { Logro: Toma de decisiones eficiente } \\
\text { para el avance oportuno de los pro- } \\
\text { yectos en los tiempos establecidos } \\
\text { evidenciando los comportamientos } \\
\text { asociados a la EA y al TC para el lo- } \\
\text { gro de los objetivos de cada comité. }\end{array}$ & $\begin{array}{l}\text { - Se propició la escucha de } \\
\text { todos los colaboradores por } \\
\text { medio de la práctica del } \\
\text { "Daily meeting" en las } \\
\text { áreas, en donde se impul- } \\
\text { saba la participación de } \\
\text { aquellos colaboradores que } \\
\text { quisieran comentar los } \\
\text { avances e ideas de los pro- } \\
\text { cesos o proyectos en los } \\
\text { cuales estaban involucra- } \\
\text { dos. } \\
\text { Logro: Esto permitió la } \\
\text { toma de decisiones opor- } \\
\text { tuna para un mayor avance } \\
\text { de los procesos y proyectos } \\
\text { en donde estaban involucra- } \\
\text { dos los colaboradores, así } \\
\text { como el relevamiento de } \\
\text { nuevas ideas y opiniones de } \\
\text { los colaboradores por parte } \\
\text { de los líderes sobre los dife- } \\
\text { rentes proyectos que cada } \\
\text { uno mencionaba eviden- } \\
\text { ciando así aquellos compor- } \\
\text { tamientos asociados a la } \\
\text { EA. }\end{array}$ \\
\hline
\end{tabular}




\section{APÉNDICE 9 MATRIZ ORGANIZATIVA DEL PROY- ECTO}

\begin{tabular}{|c|c|c|c|}
\hline Objetivo General & Competencia General & Resultados Específicos & Indicadores \\
\hline 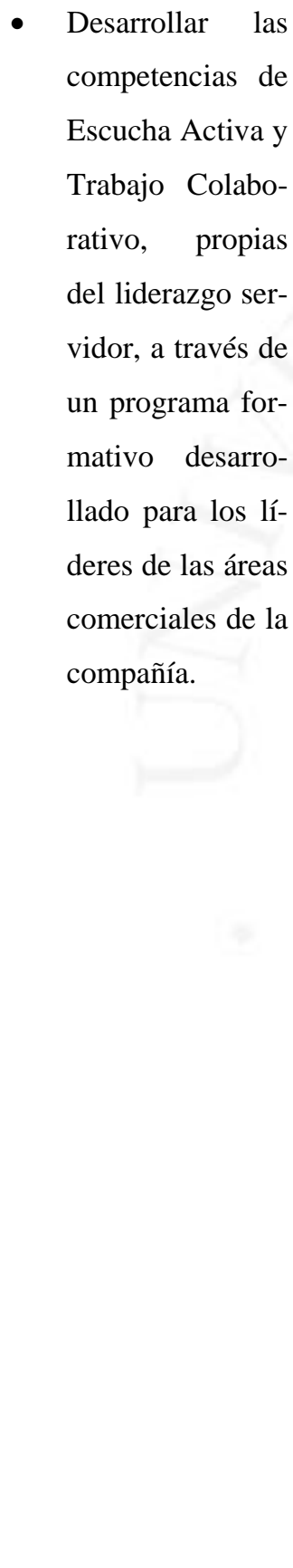 & $\begin{array}{l}\text { Escucha Activa: Escu- } \\
\text { chan y aceptan diferen- } \\
\text { tes opiniones, no se an- } \\
\text { ticipan a brindar una } \\
\text { respuesta, no juzgan y } \\
\text { no interpretan las pro- } \\
\text { puestas de los colabo- } \\
\text { radores. } \\
\text { Trabajo Colaborativo: } \\
\text { Logran llegar a con- } \\
\text { sensos, intercambian } \\
\text { opiniones mediante re- } \\
\text { troalimentación cons- } \\
\text { tante y se apoyan para } \\
\text { el logro de los objeti- } \\
\text { vos. }\end{array}$ & $\begin{array}{l}\text { - Reconocen la importancia de la } \\
\text { escucha activa y del trabajo co- } \\
\text { laborativo en su rol como líde- } \\
\text { res. } \\
\text { - Los líderes conocen comporta- } \\
\text { mientos y actitudes asociados a } \\
\text { la EA y al TC, tales como escu- } \\
\text { char y aceptar diferentes opinio- } \\
\text { nes, no anticiparse a brindar una } \\
\text { respuesta, no juzgar ni interpre- } \\
\text { tar las propuestas de los colabo- } \\
\text { radores, la importancia de llegar } \\
\text { a consensos, realizar retroali- } \\
\text { mentación contante y apoyarse } \\
\text { para el logro de los objetivos. } \\
\text { Los líderes incorporan los com- } \\
\text { portamientos y actitudes asocia- } \\
\text { dos a la EA y al TC durante el } \\
\text { desarrollo y ejecución de sus } \\
\text { proyectos, así como en el direc- } \\
\text { cionamiento de sus equipos lle- } \\
\text { vando a cabo dos proyectos con } \\
\text { sesiones de trabajo colabora- } \\
\text { tivo, creando un Comité Inter- } \\
\text { disciplinario donde evidencia- } \\
\text { ron las conductas de EA y TC y } \\
\text { generando Daily Meetings en } \\
\text { sus áreas aplicando así las con- } \\
\text { ductas de EA. }\end{array}$ & $\begin{array}{l}\text { - Creación de sesio- } \\
\text { nes de trabajo cola- } \\
\text { borativo para el } \\
\text { desarrollo de } 2 \text { pro- } \\
\text { yectos de la com- } \\
\text { pañía. } \\
\text { - Creación de Co- } \\
\text { mité Interdiscipli- } \\
\text { nario evidenciando } \\
\text { la aplicación de } \\
\text { conductas de EA y } \\
\text { TC. } \\
\text { Creación de Daily } \\
\text { Meeting en las } \\
\text { áreas evidenciando } \\
\text { la aplicación de la } \\
\text { EA. }\end{array}$ \\
\hline
\end{tabular}

